Cahiers Charlevoix

Études franco-ontariennes
Cahiers Charlevoix Études franco-ontariennes

or Crevenerix of

\title{
« Danser sur ses bas ». Rémanence d'une sanction populaire dans le rituel du mariage franco-ontarien
}

\section{Jean-Pierre Pichette}

Volume 5, 2002

URI : https://id.erudit.org/iderudit/1039354ar

DOI : https://doi.org/10.7202/1039354ar

Aller au sommaire du numéro

\section{Éditeur(s)}

Société Charlevoix

Presses de l’Université d'Ottawa

ISSN

1203-4371 (imprimé)

2371-6878 (numérique)

Découvrir la revue

Citer cet article

Pichette, J.-P. (2002). « Danser sur ses bas ». Rémanence d'une sanction populaire dans le rituel du mariage franco-ontarien. Cahiers Charlevoix, 5, 229-311. https://doi.org/10.7202/1039354ar
Résumé de l'article

Jean-Pierre Pichette s'intéresse à un rituel du mariage très vivant et coloré en Ontario français, la " danse sur les bas ", connu dans le Sud-Ouest dans une variante, la "danse dans l'auge ». Pour cerner les principales manifestations et saisir l'évolution d'une pratique rarement rapportée au Canada français et qui n’avait jamais été étudiée en Ontario avant cette étude, il a ordonné une enquête et fait appel à de nombreux collègues et à des collaborateurs étudiants. La comparaison des centaines de témoignages réunis, franco-ontariens et canadiens-français, lui permet de décrire les formes particulières et régionales du rituel - la danse dans l'auge, dans une cuve et sur ses bas -, de suivre leur évolution et d'apprécier leur degré de vitalité dans les milieux minoritaires. L'examen des conditions historiques qui ont soutenu cette coutume - connue au temps des Papineau -, et du climat culturel favorisant sa durée et son expansion met en évidence la nécessité en ethnologie d'un terrain permanent, qui, en plus d'enrichir la connaissance, participe à l'abolition des préjugés. 
À deux grands ethnologues de terrain, Simonne Voyer, dont les travaux fondent les études en danse au Canada français, et Jean-Claude Dupont, qui, le premier, consigna cette tradition.

\section{«DANSER SUR SES BAS». \\ RÉMANENCE D'UNE SANCTION POPULAIRE DANS LE RITUEL DU MARIAGE FRANCO- ONTARIEN}

Jean-Pierre Pichette

Département de folklore et ethnologie

de l'Amérique française

Université de Sudbury, Sudbury

Cahiers Charlevoix 5, 2002, pp. 229-311 


\section{SOMMAIRE}

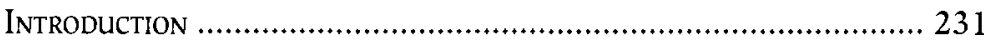

L'ethnologie franco-ontarienne ...................................... 231

Un chantier à poursuivre .................................................. 233

Préjugés et recherche documentaire ................................... 235

I - LA TRAJECTOIRE D'UN RITUEL DU MARIAGE ................................ 237

A. Une sanction populaire …....................................... 237

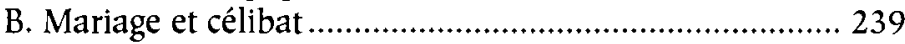

1. Le présent du roi

2. La chanson

3. La langue populaire

C. «Danser en semelles de bas»

au temps des Papineau ....................................................... 246

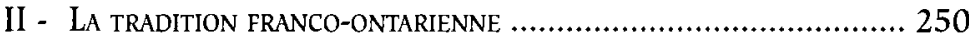

A. «Danser sur ses bas" en Ontario français ...................... 250

1. La danse sur les bas

2. La danse dans l'auge

3. De l'auge à la cuve

4. Une tradition mixte

B. Caractéristiques du rituel ...........................................2 274

III - Une tradition des Français d’Amérique ............................... 280

A. "Danser dans l'auge"

ou «danser sur ses bas» au Québec 280

1. Danser sur ses bas

2. Danser dans l'auge

3. Danser dans une cuve

B. «La danse dans l'auge» en Acadie ............................... 288

C. Répartition canadienne et nord-américaine ................... 296

Conclusion

De la nécessité d'un terrain permanent

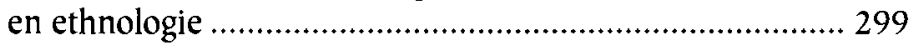

ANNEXE: «MANGer DE L'AVoine» et «Donner la PelLE» ..................... 303 


\section{«DANSER SUR SES BAS». RÉMANENCE D'UNE SANCTION POPULAIRE DANS LE RITUEL DU MARIAGE FRANCO- ONTARIEN}

«En science, c'est rare que l'on soit bredouille quand on fait du terrain'."

\section{INTRODUCTION}

L'ETHNOLOGIE FRANCO-ONTARIENNE

La prospection véritable des traditions populaires francoontariennes est une entreprise contemporaine qui n'a débuté qu'après la Deuxième Guerre mondiale, il y a un peu plus d'une cinquantaine d'années. C'est au père Germain Lemieux, s.j., qu'on doit ce premier effort soutenu d'exploration du milieu franco-ontarien. La publication des trentetrois tomes de la série Les vieux m'ont conté2, dont la moitié concerne l'Ontario français, ne représente que la partie narrative d'une collection commencée en septembre 1948 et qui s'est poursuivie jusqu'au début des années 1980. Un lustre avant ce vénérable jésuite, en 1943, Joseph-Médard

\footnotetext{
${ }^{1}$ Parole d'Yves Coppens, paléontologue français, prononcée au cours d'une entrevue à l'émission "Le Point", diffusée à la Société Radio-Canada (Montréal) le 21 mai 2001 et rediffusée le 11 juillet 2001.

2 Germain Lemieux, Les vieux m'ont conté, Montréal, Bellarmin; Paris, Maisonneuve et Larose, 1973-1993, 33 vol.
} 
Carrière (1902-1970) avait bien recueilli deux douzaines de contes dans la région du Sud-Ouest, tout comme FrançoisJoseph Brassard (1908-1976) avait consigné quelques centaines de chansons dans certains villages du Nord entre 1943 et 1948; mais ces recherches furent isolées et sans suite, comme l'avaient été aussi les cueillettes épisodiques de l'archiviste Édouard-Zotique Massicotte (1867-1947), de l'écrivain Marie-Rose Turcot (1887-1977) et des autres collaborateurs de Marius Barbeau (1883-1969) qui évoluèrent dans l'est ontarien entre les deux guerres ${ }^{3}$.

L'accession à l'autonomie du Centre franco-ontarien de folklore (CFOF) en 1972, qui se détachait de l'Université de Sudbury en 1981 pour faire fructifier la collection du père Lemieux, amena le département de Folklore (et ethnologie) à implanter son propre dépôt d'archives afin de conserver les travaux de terrain que les professeurs et les étudiants effectuaient dans le cadre de leurs activités pédagogiques. À la fin de l'année 2001, qui marquait la clôture des célébrations du vingt-cinquième anniversaire de fondation de l'enseignement de l'ethnologie en Ontario français (1975-2000), on dénombrait 1231 collections entreposées dans ces archives et on évaluait le nombre des pièces qu'elles contiennent à environ 32700 . Voilà le deuxième effort qui se poursuit toujours.

De 1991 à 1994, le Centre franco-ontarien de folklore, de concert avec notre département, lançait, sous la direction de Gaétan Gervais et de Jean-Pierre Pichette, les concepteurs et conseillers scientifiques, un vaste projet d' «Inventaire du patrimoine franco-ontarien», dont on confia la coordination à Serge Saint-Pierre. Durant trois ans, des équipes ratissèrent tout le territoire ontarien à la recherche des traces visibles de sa population française:

\footnotetext{
${ }^{3}$ Pour une description de ces travaux et une première synthèse de la recherche dans ce terroir, voir notre Répertoire ethnologique de l'Ontario français. Guide bibliographique et inventaire archivistique du folklore franco-ontarien, Ottawa, Presses de l'Université d'Ottawa [PUO], 1992, X-230 pages.
} 
330 dossiers ethnohistoriques, 24000 photographies relatives aux 4600 sites repérés témoignent aujourd'hui de leurs activités et forment la seconde banque documentaire du CFOF ${ }^{4}$. C'est là le troisième effort d'importance.

\section{UN CHANTIER À POURSUIVRE}

Est-ce à dire que ces campagnes de collecte des traditions orales et matérielles ont à tout jamais épuisé les sources du patrimoine français de cette province? Ou, comme des chercheurs de cabinet l'ont naguère prétendu ailleurs, qu'on a maintenant rassemblé suffisamment de données pour alimenter les travaux qu'on en pourrait tirer, que l'ère des catalogues est enfin révolue et que, dorénavant, l'heure est à la synthèse et à la théorie? Ce sont là des erreurs qui ne sont pas nouvelles.

Il faut bien reconnaître que les grands champs de l'ethnologie n'ont pas tous été touchés par les recherches jusqu'ici menées en Ontario et, même pour la littérature orale qui a principalement retenu l'attention (conte, légende et chanson), que les chercheurs ont restreint leur enquête à une partie du domaine (le conte merveilleux en particulier) et du territoire (la grande région de Sudbury, située dans le Nord-Est). Le champ coutumier, par exemple, dans lequel s'inscrit cette étude, n'a fait encore l'objet d'aucune cueillette systématique. Ainsi, pour des raisons diverses - insuffisance de personnel, prédisposition pour d'autres secteurs, engagements qui éloignent du terrain, manque de temps, désintéressement ou négligence - certaines traditions passent inaperçues des chercheurs, parce qu'elles vivent en marge de leurs activités. D'autre part, au sein même de la population qui les détient, elles ne reçoivent pas toute la considération qu'elles méritent, car, s'il en est des traditions

\footnotetext{
${ }^{4}$ La synthèse de cet inventaire est maintenant disponible: [Centre francoontarien de folklore], Habiter le pays. Inventaire du patrimoine de l'Ontario français, Sudbury, Centre franco-ontarien de folklore et Prise de parole, 2001, 270 pages.
} 
comme des individus, personne ne saurait se vanter de les connaître toutes; ceux qui les connaissent et qui les ont pratiquées durant leur vie peuvent être rares, vieillissants, concentrés dans une région à l'écart et inconnus des autres; de plus, ils ne se rendent pas toujours compte qu'un usage très courant chez eux n'existe pas ailleurs, ou encore qu'il possède des traits régionaux particuliers. La bénédiction paternelle du jour de l'An, par exemple, est une tradition familiale ancienne et bien connue, mais elle n'est pas universelle; son caractère de relative intimité fait souvent qu'elle sera pratiquée dans une famille et totalement inconnue dans son voisinage. Dans ces conditions, il est possible que des pratiques, qui furent communes en leur temps, meurent sans jamais avoir été décrites. Il en eût vraisemblablement été ainsi de la "quête des chandelles", une coutume complètement disparue depuis plus d'un siècle, qui n'aurait laissé d'autre trace que le souvenir de jeunesse rapporté par l'abbé Camille Roy en 1910; grâce à son témoignage, on sait que cette tournée était exécutée, avant l'ère des lampes à pétrole, par les jeunes gens, qui passaient de maison en maison afin de recueillir les chandelles qui illumineraient l'église pour la messe de minuit, la veille de Noël ${ }^{5}$. D'où la plus grande circonspection quand vient le temps d'affirmer l'existence ou l'absence d'une tradition dans un milieu donné. L'a-t-on d'abord cherchée? Si oui, l'a-t-on ensuite recueillie et consignée dans des archives ou des publications? Sinon, prudence! La réponse mesurée d'un chercheur avisé, à notre enquête sur l'existence dans son coin de pays de la danse à l'étude, mérite d'être ici rapportée pour sa sagesse: "Je ne la connais pas personnellement, mais je ne l'ai jamais recherchée. Je vais interroger les gens à mon retour. Ensuite, je pourrai vous répondre ${ }^{6} . »$

\footnotetext{
5 «Noël rustique (pour le 24 décembre)», billet daté de décembre 1910, dans Camille Roy, Propos canadiens, Québec, Imprimerie de l'Action sociale, 1912, pp. [59]-68; voir surtout les pp. 60-62 qui rapportent un souvenir d'enfance de l'auteur (1871-1943), qu'il faut situer vers 1875 à Berthier-en-Bas (Montmagny).

${ }^{6}$ Rencontré à Windsor en juillet 2001, Dennis Au devait par la suite nous
} 
PRÉJUGÉS ET RECHERCHE DOCUMENTAIRE

En 1982, au cours d'une noce dans la banlieue de Sudbury, nous avions déjà été témoin d'un rituel où la sœur aînée du marié avait dû danser sur ses bas. Absorbé alors par d'autres travaux, nous avons consigné le fait sans plus, peut-être intérieurement convaincu que cette tradition, attestée dans une région minoritaire, et par surcroît inconnue dans nos enquêtes auprès d'une majorité canadiennefrançaise, le Québec d'où nous sommes originaire, ne pouvait qu'avoir été influencée par le milieu anglophone majoritaire. Pendant les années qui suivirent, nos étudiants de l'Université de Sudbury confirmèrent la présence et l'actualité de cette tradition: l'une décrivit d'abord l'expérience qu'elle avait vécue en dansant elle-même sur des bas rouges que la coutume de son milieu lui avait ordonné d'apporter ${ }^{7}$; cinq autres proposèrent cette cérémonie comme image traditionnelle typique de leur milieu ${ }^{8}$.

À partir de 1990, nos travaux s'orientèrent vers l'étude des échanges interculturels pratiqués entre les groupes francophones, anglophones et autochtones d'Amérique du Nord dans certains domaines des traditions orales - le conte et la chanson surtout. Ils sanctionnèrent l'importance des recherches comparatives que nos études antérieures consacrées aux jurons et au conte populaire avaient privilégiées". Dans cette perspective, la "danse sur les bas»,

confirmer par courriel que deux personnes de son entourage avaient déjà entendu parler de cette tradition chez les Canadiens français établis à Monroe, Michigan.

${ }^{7}$ Département de Folklore et ethnologie de l'Université de Sudbury [DFEUS], collection Lucie Beaupré, ms. $\mathrm{n}^{\circ} 14$ «Les Bas rouges [en Ontario]», 30 janvier 1985, 1 p.

${ }^{8} 11$ s'agit de réponses données à un exercice pédagogique du cours d'introduction au folklore entre les années 1989 et 1999.

9 Jean-Pierre Pichette, Le Guide raisonné des jurons. Langue, littérature, histoire et dictionnaire des jurons, Montréal, Les Quinze, "Mémoires d'homme", 1980, 305 pages; Id., L'Observance des conseils du maître. Monographie internationale du conte type A.T. 910 B précédée d'une introduction au cycle des bons conseils (A.T. 910-915), Sainte-Foy, Les Presses de l'Université Laval [PUL], 
proposée de façon récurrente comme signe identitaire par plusieurs étudiants franco-ontariens, revêtit un intérêt nouveau. Pendant l'hiver 1999, la reprise d'un cours sur les coutumes populaires, qui traitait des rites du berceau à la tombe, de concert avec notre enseignement sur les folklores régionaux du Canada français allaient donner le coup d'envoi à la présente recherche. Un sondage auprès de nos étudiants nous ayant révélé que tous, à de très rares exceptions, avaient été témoins du rituel, l'enquête personnelle que nous leur proposâmes porta sur ce sujet: descriptions, témoignages, photos, bandes vidéo, tout concourait à montrer l'ampleur de ce rite de passage en milieu franco-ontarien en même temps que sa relative ancienneté ${ }^{10}$. La publication d'une première version franco-ontarienne, dans le bulletin d'information départemental, en découla ${ }^{11}$.

Cette investigation initiale fut déterminante et mena à l'élaboration d'un questionnaire d'enquête ${ }^{12}$ pour une recherche sur le terrain avec l'assistance de deux groupes d'étudiants ${ }^{13}$; trois d'entre eux acceptèrent même d'en faire le sujet de leur enquête spécialisée ${ }^{14}$. Parallèlement à cette cueillette des données, qui formera une banque de 359 répondants répartis à la grandeur du Canada, nous avons

"Archives de folklore" 25; Helsinki, Academia Scientiarum Fennica, «Folklore Fellows Communications» 250, 1991, XX-671 pages.

${ }^{10}$ Ces collaborateurs étudiants furent Vicky Ayotte, Cindy Grzela, Mélanie Roy, Gilles Paquette (FOLK-2117, hiver 1999); Anne Champagne, Mélanie Démoré, Ronald Hogue, Lisa Rainville, Nathalie Rheault (FOLK-2226, hiver 1999); Isabelle Brochu et Marko Roy, assistants de recherche, apportèrent aussi leur collaboration.

${ }^{11}$ «La Danse sur les bas à Moonbeam [version de Nathalie Rheault]», dans La Criée, Sudbury, Université de Sudbury, DFEUS, n²3, décembre 1999, p. 2.

${ }^{12}$ J.-P. Pichette, «Danser sur ses bas. Questionnaire d'enquête», Sudbury, $1^{\text {er }}$ avril 1999, [1]-4 pages.

${ }^{13}$ Le premier groupe comprenait Estelle Corriveau, Fritz-Gérald Destiné, Annie Gagné, Sophie Laflamme, Eding Mvilongo, Jacinthe Trudeau (FOLK-2117, hiver 2000).

${ }^{14}$ Il s'agit de Donald Albert, Gisèle Jodoin et Danielle Lauzon, inscrits au cours FOLK-3516 durant l'année 2000-2001; la collaboration de ces trois étudiants a grandement contribué à étendre notre enquête dans les régions du centre, de l'est et du nord-est de l'Ontario. 
étendu notre consultation à des chercheurs, collègues et autres experts du Canada, français et anglais, des ÉtatsUnis, ainsi que de l'Europe francophone et anglophone, au moyen d'une lettre circulaire. Distribuée à 125 personnes au cours de l'été 1999 , elle nous avait procuré une quarantaine de réponses au début de l'automne suivant. Des contrôles complémentaires, en archives et en bibliothèques, la rédaction d'une note de recherche ${ }^{15}$ tout comme, enfin, les échanges qui ont suivi la communication, dans le cadre de colloques et congrès, des premiers résultats de nos travaux ont considérablement enrichi notre projet ${ }^{16}$. C'est du dépouillement de tous ces témoignages que nous tirons la matière de cette étude.

\section{I - La trajectoire d'Un Rituel du Mariage}

\section{A. UNE SANCTION POPULAIRE}

On observe, de façon constante et depuis longtemps chez beaucoup de peuples, une même règle élémentaire et naturelle qui jalonne le cours normal de la vie humaine et qui pourrait se résumer par cette formulation toute simple: le respect de la primogéniture ${ }^{17}$, du rang que donne la naissance et de l'ordre que ce rang prescrit. Selon cette règle, dans le cas particulier du mariage, l'aîné doit se

\footnotetext{
${ }^{15}$ J.-P. Pichette, «Note de recherche. Un rituel du mariage en Ontario français", dans L'Ethnologie... en bref, bulletin de la Société québécoise d'ethnologie, Québec, vol. 2, n 2 , Hiver 2000, pp. 5-8.

${ }^{16}$ «La Dynamique d'un rituel du mariage. Terrains communs entre la France, l'Acadie et l'Ontario" au congrès international de l'Institut d'études acadiennes et québécoises, «L'Acadie plurielle en l'an 2000 ", à l'Université de Poitiers, le 26 mai 2000; "Danser dans une auge ou danser sur ses bas. Examen d'un rituel du mariage franco-ontarien» au colloque international «Le Passage du Détroit: 300 ans de présence francophone", à l'Université de Windsor, le 20 juillet 2001; et une dernière version portant le même titre au congrès de l'Association canadienne d'ethnologie et de folklore, à l'Université de Sudbury, le 25 mai 2002.

${ }^{17}$ Puisque nous ne considérons ici que l'obligation de l'aîné de se marier le premier et non un quelconque privilège qui lui serait accordé dans la transmission du patrimoine familial, nous avons préféré ce mot à "droit d'aînesse".
} 
marier d'abord et les cadets ensuite. Edward Westermarck, dans son Histoire du mariage, énumère plusieurs peuples qui ont observé cette coutume; il cite aussi la Bible: «Laban dit: on ne doit pas faire ainsi dans notre pays, épouser la cadette avant la première née» (Genèse, XXIX, 26) ${ }^{18}$. Au Canada français, les données démographiques vont également dans ce sens. Parlant de l'établissement des enfants, Gérard Bouchard confirme cette tendance pour le Saguenay, qu'il a spécialement étudié, et remarque:

Ce processus suivait d'assez près l'ordre des naissances. Dans la plupart des cas en effet $(90,9 \%$ pour les garçons, $84,6 \%$ pour les filles), l'enfant le plus âgé était le premier à se marier. D'un rang de naissance à l'autre, cette correspondance s'atténuait, mais se maintenait. Ainsi, même chez les enfants nés au cinquième rang, près de la moitié des fils $(46,7 \%)$ et des filles $(42,9 \%)$ se mariaient dans cet ordre. Lorsqu'on considère les rangs de mariage des filles et des garçons ensemble, on observe que les premières "volaient» souvent leur rang aux seconds, ce qui est simplement attribuable au fait qu'elles se mariaient habituellement plus jeunes ${ }^{19}$.

S'il y a dérogation à cette règle commune, la collectivité, par ses instances familiales ou villageoises, doit intervenir. Plus qu'une affaire de "vie privée» ou personnelle, elle y voit une infraction publique, qui contrevient à la stabilité de la vie communautaire. Elle peut en conséquence retarder le mariage du cadet, comme on le voyait fréquemment autrefois et encore de nos jours dans certains pays, mais, dans nos sociétés modernes plus complaisantes, elle exigera plutôt un acte compensatoire de la part de l'aîné pris en faute.

Cette compensation prendra l'allure d'un rituel à accomplir, comme une amende honorable venant temporairement

\footnotetext{
${ }^{18}$ Edward Westermarck, Histoire du mariage, traduit de l'anglais par Arnold Van Gennep, Troisième édition, Paris, Mercure de France, 1935, tome II, pp. 111-112.

${ }^{19}$ Gérard Bouchard, Quelques Arpents d'Amérique. Population, économie, famille au Saguenay 1838-1971, [Montréal], Boréal, [1996], p. 201.
} 
tolérer ou excuser un comportement socialement inadmissible, une permission provisoire en quelque sorte, qui vise d'abord à exposer publiquement le dérogateur et à déplorer sa conduite. La dérogation entraîne ainsi une sanction.

Le meilleur moment pour l'exécution de cette sentence coutumière survient au cours du grand rassemblement des noces. Parfois la veille, mais le plus souvent le jour même du mariage paraît l'occasion propice de stigmatiser symboliquement le délit de dissidence sociale du dérogateur. Le lieu de la noce, autrefois la maison de la nouvelle mariée, de nos jours une salle de réception commerciale, procure le décor et l'assemblée touchée par ce méfait symbolique et sa sanction qui l'est tout autant.

Il a existé plusieurs formes au Canada pour cette sanction, mais presque toujours dans le cadre d'une danse.

\section{B. MARIAGE ET CÉlibAT}

1. Le présent du roi

Il faut bien rappeler qu'à moins d'entrer en religion, vocation perçue comme une bénédiction pour la famille, ou de se faire le «bâton de vieillesse» de ses vieux parents en se dévouant à leur service, sacrifice également bien accepté, on n'a jamais encouragé le célibat au Canada français. Au contraire, les moqueries ont régulièrement sanctionné les «vieux garçons» et les «vieilles filles" qui avaient atteint l'âge de 25 ans sans s'être mariés. La pression sociale était telle que, même dans les années 1970 et sans doute au-delà, les allusions malveillantes couraient encore à l'endroit des "vieux garçons» et qu'on rappelait aux filles qu'elles allaient "coiffer sainte Catherine» le 25 novembre, fête de la patronne des «vieilles filles». Si des facteurs sociaux, comme les études prolongées et le taux élevé du divorce, ont de nos jours une incidence réelle sur l'âge du mariage et contribuent à le retarder, cette tendance contraste avec la mentalité populaire qui plonge ses 
racines dans des habitudes acquises de longue date et dont les manifestations remontent parfois aux premiers temps de la colonie française en Amérique.

D'une part, les autorités civiles réclamaient alors l'établissement à demeure des colons et multipliaient les exhortations à se marier et à fonder des familles nombreuses. L' «arrêt du Conseil d'État du Roi pour encourager les mariages des garçons et des filles du Canada", daté du 12 avril 1670 et publié à Québec par le Conseil souverain le 20 octobre suivant, établissait une pension annuelle en faveur des familles nombreuses:

en considération de la multiplicité des enfants et pour les porter au mariage, Sa dite Majesté, étant en son conseil, a ordonné et ordonne qu'à l'avenir tous les habitants du dit pays qui auront jusqu'au nombre de dix enfants vivants, nés en légitime mariage, non prêtres, religieux ni religieuses seront payés des deniers que Sa Majesté envoyera au dit pays, d'une pension de trois cents livres par chacun an, et ceux qui en auront douze, de quatre cents livres.

De plus, le roi ordonnait de verser «à tous les garçons qui se marieront à vingt ans et au-dessous, et aux filles à seize ans et au[-]dessous, vingt livres pour chacun le jour de leurs noces, ce qui sera appellé [sic] le présent du roi»; le même arrêt prévoyait même une amende contre les pères qui n'auraient pas marié leurs enfants avant ces âges ${ }^{20}$. En outre, l'ordonnance promulguée l'année suivante, le 20 octobre 1671, par l'intendant Talon portait en son titre les peines qu'encourraient les célibataires récalcitrants: «Ordonnance pour forcer les célibataires à épouser les filles qui arrivent de France sous peine d'être privés des privilèges de pêche, chasse et traite des fourrures ${ }^{21} \%$. Pour sa

${ }^{20}$ Édits, ordonnances royaux, déclarations et arrêts du conseil d'État du roi concernant le Canada, Québec, de la presse à vapeur de E.R. Fréchette, 1854, pp. 67-69.

2: Pierre-Georges Roy, Inventaire des ordonnances des intendants de la NouvelleFrance conservées aux Archives provinciales de Québec, Beauceville, l' 'Éclaireur», vol. 3, 1919, p. 266. Robert-Lionel Séguin examine cette question dans La Civilisation traditionnelle de l'"habitant" aux $17^{e}$ et $18^{e}$ siècles. 
part, l'Église favorisait aussi les unions précoces puisqu'elle permettait le mariage des filles dès l'âge de 12 ans et celui des garçons à 14 ans $^{22}$.

Il est clair que, dans un tel contexte, se marier jeune était bien reçu et socialement encouragé; retarder l'âge de son mariage, c'est-à-dire après seize ans pour les filles et vingt ans pour les garçons, était perçu comme une déroga tion aux règles établies et sujet à une amende à payer par les parents et à la perte de privilèges pour le célibataire. Aussi, quand un cadet devançait son aîné, la famille ne considérait pas qu'il brimait le droit d'aînesse, mais plutôt que l'aîné devait être puni pour ne pas l'avoir exercé en son temps.

Par ailleurs, il est difficile de savoir si les ordonnances du roi et de l'intendant contribuèrent vraiment à abaisser l'âge moyen du mariage qui était, selon le démographe Hubert Charbonneau, pour les filles de 20,9 ans et de 28,8 ans pour les garçons au XVII ${ }^{\mathrm{e}}$ siècle ${ }^{23}$. Si ces législations eurent un impact, il fut fort probablement de peu d'importance, compte tenu qu'il manquait de femmes: on dénombrait «six à sept hommes mariables pour une femme au moment où le roi prend la colonie en main ${ }^{24} »$. Mais, chez les femmes, la tendance à se marier tôt était bien réelle. Considérant l'écart d'âge entre les époux, Charbonneau note:

Quand l'épouse est une célibataire née au Canada, la différence d'âge s'élève à près de 14 ans, en raison de la grande précocité des premières filles nées dans la colonie: près des deux

Fonds matériel, $2^{\mathrm{e}}$ édition revue, Montréal, Fides, [1973], pp. 280-290.

${ }^{22}$ Raymond Boyer traite des cinq cas de mariage où la mariée n'avait que 11 ans dans Crimes et châtiments au Canada français du XVII au XIX siècle, Montréal, Cercle du livre de France, "L'Encyclopédie du Canada français» V, [1966], pp. 317-318.

${ }^{23}$ Hubert Charbonneau et al., Naissance d'une population. Les Français établis au Canada au XVII ${ }^{e}$ siècle, Montréal, Presses de l'Université de Montréal, et Paris, Presses universitaires de France, Institut national d'études démographiques, "Travaux et documents» cahier $n^{\circ} 118,1987$, p. 71.

${ }^{24}$ Ibid., p. 58, selon les calculs de Marcel Trudel. 
tiers d'entre elles se marient avant 15 ans. Non seulement tous les maris sans exception sont alors plus âgés que leur femme, mais l'écart atteint au moins dix ans plus de quatre fois sur cinq ${ }^{25}$.

Dans les siècles qui suivirent, bien que la propension à se marier très jeune reculât, il appert que les femmes mariées de 15 à 19 ans composaient encore $10,2 \%$ des mariages en $1852,7,7 \%$ en $1871,5,7 \%$ en 1891 et $5,4 \%$ en $1911^{26}$. Au Saguenay, avant 1940 , on a constaté que «l'âge moyen des filles à leur premier mariage a oscillé entre 20 et 21 ans, alors que celui des garçons variait entre 24 et 25 ans $^{27}$ ").

\section{La chanson}

La chanson populaire, pour s'en tenir à ce seul genre de la littérature orale, conserve encore de nombreuses réminiscences de la nécessité de se marier tôt, surtout pour les filles. On y présente la difficulté de dénicher un partenaire chez les unes:

À la fact'rie d' tabac,

Des filles il y en a

Qui veul'nt se marier,

Mais i[ls] ne peuvent pas trouver ${ }^{28}$.

Cela expliquerait pourquoi certaines paraissent se contenter du premier amoureux qui passe, fût-il peu attirant:

J'me su[i]s fait un amant, il $y$ a pas longtemps:

I[I] a [au]tant d' poux sur la tête comme il a de cheveux.

Ie l' veux à ma fantaisie,

Pas d'aut[r]' que lui, je l' veux,

C'est mon amoureux ${ }^{29}$.

${ }^{25}$ Ibid., p. 73.

${ }^{26}$ Jacques Henripin et Yves Peron, «La Transition démographique de la province de Québec", dans Hubert Charbonneau, La Population du Québec: études rétrospectives, [Montréal], Éditions du Boréal Express, "Études d'histoire du Québec» 4, [1973], p. 38.

${ }^{27}$ Gérard Bouchard, op. cit., p. 257, citant une étude de Danielle Gauvreau.

${ }^{28}$ Coll. J.-P. Pichette, enreg. 2517, extrait de la version de D. Paradis chantée à Blezard-Valley, Sudbury, Ontario, le 30 juillet 1982: VI-A-[n. cl.] $A$ la facterie de tabac.

${ }^{29}$ Coll. J.-P. Pichette, enreg. 2415, extrait de la version de D. Paradis chantée à Blezard-Valley, Sudbury, Ontario, le 21 juillet 1982: IV-Fa-1 L'Amant laid. 
"Danser sur ses bas». Rémanence d'une sanction populaire

Nombreuses sont aussi les chansons où les jeunes filles déclarent à leurs parents leur impatience de se marier:

C'est un' jeune orpheline

À l'âge de quinze ans;

Un jour dit à son père,

À son père en pleurant:

- Mon pèr', mon tendre père,

Laissez-moi, c'est mon affaire,

Laissez-moi faire à mon goût:

Laissez-moi prendre un époux ${ }^{30}$.

D'autres pressent leurs parents de les marier et, malgré les réticences de ces derniers qui tentent vainement de les raisonner, elles font preuve d'une débrouillardise inouïe pour convoler à tout prix:

1. La fille - Mon père, il me faut un mari!

Depuis longtemps, je vous le dis.

Qu'il soy' très doux, qu'il soy' tendre

Pour moi, je ne peux plus attendre,

Mariez-moi, car il est temps:

Faites-moi publier des bans.

2. Le père - Ma fill', mais faut attendre un p'tit moment

[Pour te fair' publier un ban,

Car, dans l'état du mariage,

Il vous faut un petit ménage.]

Ce garçon-là n'a pas l' moyens

De t'épouser-z-avec-que rien.

3. La fille - Ma mèr', vous ne le connaissez pas.

Comment font ceus's qui n'en ont pas?

J'ai d' l'argent dans ma cassette

Pour acheter couteaux, fourchettes,

Cuiller à pot, poêle à fourneau,

Un potager, un pot' à l'eau.

4. Je vend-e-rai aussi mon tablier

C'est pour me fair' des d'ssus d'oreillers;

Je vend-e-rai aussi ma coiffure

${ }^{30}$ Coll. J.-P. Pichette, enreg. 2458, extrait de la version de D. Paradis chantée à Blezard-Valley, Sudbury, Ontario, le 21 juillet 1982: II-O-38 L'Orpheline promise au couvent. 
C'est pour m'ach'ter des couvertures, Une couchette basse, un tour de lit;

Nous nous gréy'rons de p'tit en p'tit ${ }^{31}$.

Par ailleurs, il n'est pas rare non plus que les filles se trouvent un amant avant l'âge prescrit par l'ordonnance royale de 1670 :

I'ai fait l'amour à-t-une fille

qui n'avait pas encor' quinze ans;

Ell' n'avait pas encor' quinze ans,

j'allais la voir-e.

Son pèr' m'a donné-t-un congé

du désespoir-e $\mathrm{e}^{32}$.

Ou prennent mari:

Par un lundi matin, Rosette se marie (bis)

Avec un vieux de quatre-vingt-dix ans,

La p'tit' Rosette qui n'avait que quinze ans ${ }^{33}$.

Car, plus que le regret des maumariées, il faudrait, d'après la pièce suivante, davantage craindre le regret des «vieilles filles enragées » :

1. Par un dimanche au soir,

Dans mon chemin rencontre

en m'en allant veiller, un' vieill' fill' qui pleurait.

I' suis pas capable,

Sur la montagn'du loup

I' suis pas capable

Sur la montagn' du loup

I' suis pas capabl' d'y arriver.

2. Je lui ai demandé:

"Qu'avez-vous à pleurer?

3. - Je pleur', je suis vieill' fille, j'ai pas pu m'en trouver.

4. J'arrive en l'autre monde

l' visag' tout massacré.

5. Saint-Pierr' qu'est à la porte

6. Car il m'a demandé: veut pas m' laisser entrer. «Êtes-vous mariée?»

\footnotetext{
${ }^{31}$ Coll. J.-P. Pichette, enreg. 2416, extrait de la version de D. Paradis chantée à Blezard-Valley, Sudbury, Ontario, le 11 juillet 1982: III-C-1 I Ma fille, nous n'avons pas assez d'argent.

${ }^{32}$ Coll. J.-P. Pichette, enreg. 2405, extrait de la version de D. Paradis chantée à Blezard-Valley, Sudbury, Ontario, le 11 juillet 1982: II-C-1 1 Le Rendez-vous de nuit.

${ }^{33}$ Coll. J.-P. Pichette, enreg. 2549, extrait de la version de D. Paradis chantée à Blezard-Valley, Sudbury, Ontario, le 2 août 1982: II-O-54 La Petite Rosette.
} 
7. J'ai bien cherché partout, j'ai pas pu m'en trouver.

8. Vous autr's, mes jeunes filles, tâchez d' vous marier!

9. Car la mort d'un' vieill' fille, c'est un' mort enragée ${ }^{34}$.

Au moins une, cependant, évoque la concurrence entre deux sœurs dont l'aînée sera rejetée: «La Cadette mariée avant l'aînée ${ }^{35} »$. Cette chanson type représente la plus proche allusion au thème de notre étude.

1. - Bonjour, madame Mignon, je suis heureux de vous dire Que je suis venu ici ni pour chanter ni pour rire.

Au fond dl-la, dl-il, dl-la, dl-il, dl-la, Au fond dl-la, lan-lire (bis)

2. Mais, je suis venu ici, c'est pour une de vos filles.

- Laquell' prendrez-vous des deux, la plus jeune ou la plus vieille?

3. - La plus jeun' si vous voulez, car elle est la plus jolie. La plus vieille est dans son coin: elle ne fait que pleurer.

4. - Ah! Ne pleurez donc pas tant! C'est un mangeur de "poutines"!

Ne perdez pas le bon sens pour un marmiton d' cuisine ${ }^{36}$.

\section{La langue populaire}

La langue franco-canadienne possède un certain nombre d'expressions qui évoquent le fait pour un amoureux d'être éconduit par la jeune fille qu'il fréquente ou d'être supplanté par un autre prétendant. "Manger de l'avoine», "recevoir sa pelle», "se faire couper l'herbe sous les pieds», et bien d'autres encore que nous n'avons pas spécialement recherchées, sont jugées déshonorantes par la victime ${ }^{37}$.

\footnotetext{
${ }^{34}$ Pères Daniel et Anselme, capucins, Chansons d'Acadie, $3^{\mathfrak{e}}$ série, Moncton, Éditions des Aboiteaux, 1977 [1948], p. 19: "Sur la montagne du loup» (I-M-7 La Vieille Fille enragée).

${ }^{35}$ Conrad Laforte, Le Catalogue de la chanson folklorique française, Québec, PUL, «Archives de folklore» 18, 1977, vol. 1, pp. 250-252: I-G-19 La Cadette mariée avant l'aînée. Connue en Europe, par 3 versions belges et 28 françaises, on en a relevé 9 versions canadiennes, au Québec ( 4 v.), en Alberta ( 1 v.), au Nouveau-Brunswick ( 2 v.) et en Nouvelle-Écosse ( 2 v.).

${ }^{36}$ Pères Daniel et Anselme, capucins, op. cit., $3^{\mathrm{e}}$ série, p. 47: "Le Choix".

${ }^{37}$ Nous reportons en annexe la recension que nous avons faite des expressions «manger de l'avoine» et «donner la pelle» et les rapprochements à faire avec la tradition à l'étude.
} 
Sont-elles des survivances de rituels aujourd'hui disparus? La chose n'est pas impossible. L'expression «mettre sa main au feu", encore très courante au Canada français, est une survivance des ordalies du Moyen Âge ou jugements de Dieu; depuis longtemps disparues du système judiciaire, ces épreuves par le feu, comme celles par l'eau, permettaient de vérifier la qualité du serment qu'on prêtait devant des témoins.

Ainsi, l'évocation de législations royales, promulguées au commencement de la Nouvelle-France, la sollicitation de la littérature orale, par l'exemple de la chanson, et le recours à la langue populaire, dans ses expressions idiomatiques, montrent que la "danse sur ses bas» ou «danse dans l'auge" n'était pas une coutume isolée, absurde ou paradoxale. Bien au contraire, elle appartenait à un univers cohérent qui encourageait fortement le mariage à un âge juvénile et qui voyait dans le célibat un obstacle au peuplement rapide du pays; d'où cet empressement chez les jeunes filles à vouloir convoler avant «l'âge de quinze ans" et l'humiliation ressentie par les jeunes gens qui devaient «manger de l'avoine», parce qu'un autre prétendant les avait supplantés, ou qui avaient «reçu leur pelle». Ces lois, ces chansons et ces expressions restaurent en partie le climat qui a autorisé le développement et le maintien d'un rituel autrement inexplicable.

\section{C. «DANSER EN SEMELLES DE bAS " aU TEMPS DES PAPINEAU}

La plus ancienne mention de ce rituel du mariage est antérieure aux recherches des ethnologues. Que ceux-ci doivent recourir à des données historiques pour mettre en contexte les témoignages qu'ils enregistrent, cela tient aujourd'hui de l'évidence tant ce procédé est banal. Bien qu'elle soit moins courante, la démarche inverse n'est pourtant pas anormale et se vérifie tout autant. Alors, le document consigné plusieurs décennies ou, parfois, des siècles plus tôt, sous la forme d'une œuvre littéraire, 
picturale ou manuscrite, s'illumine d'une intelligibilité inattendue à la lueur d'une tradition contemporaine, vivante, toute chaude encore de son terroir. C'est le cas de la lettre ${ }^{38}$ que Joseph Papineau ${ }^{39}$ écrivait de Montréal, en date du 10 janvier 1826, à son fils Denis-Benjamin ${ }^{40}$. Le passage qui nous intéresse occupe le deuxième tiers de la lettre; il suit un premier paragraphe consacré aux affaires familiales et précède le dernier qui relaie le bulletin de santé de ses parents. Voici ce fragment:

Autre chose Dessaules et sa femme ${ }^{41}$, Eugenie ${ }^{42}$ et ton oncle André Papineau ${ }^{43}$ sont en ville ils se portent tous bien. Le docteur

${ }^{38}$ Il s'agit de la pièce 787 de la collection Papineau-Bourassa, conservée aux Archives nationales du Québec. Voir la "Correspondance de Joseph Papineau (1793-1840)", dans Antoine Roy, Rapport de l'archiviste de la province de Québec [RAPQ] pour 1951-1952 et 1952-1953, [Québec], Secrétariat de la Province, Rédempti Paradis, [1953], vol. 32-33, pp. 227-228. On lit à la p. 168: «La transcription des lettres a été faite sous la surveillance de Fernand Ouellet, licencié [è]s-lettres et archiviste aux Archives de la Province. C'est également lui qui a collationné le tout sur les manuscrits et qui pour plus de clarté a ajouté quelques notes. C'est un excellent travail d'édition." ${ }^{39}$ "Joseph Papineau [(1752-1841)] apparaît comme une des plus importantes figures de la période de l'initiation au régime parlementaire. Fils d'un tonnelier de Montréal, il naquit en 1752. Après ses études au Séminaire de Québec, il opta pour la profession de notaire et celle d'arpenteur; député de Montréal, de 1792 à 1805 , il revint à la Chambre de 1810 à 1814 . En 1801 , il avait acquis une partie de la seigneurie de la Petite-Nation et, en 1803, le reste. [. . ] Joseph Papineau s'occupa de la seigneurie jusqu'à sa mort en 1841 , même s'il l'avait vendue à son fils, Louis-Joseph, en 1817» (RAPQ pour 1951-1952 et 19521953, pp. 166-167). «Ces cent vingt-sept lettres de Joseph Papineau adressées surtout à son fils, Benjamin, marquent le début de la correspondance qui se trouve dans la collection Papineau-Bourassa» (Ibid., p. 167).

${ }^{40}$ "Denis-Benjamin Papineau (1789-1854) s'occupa de la Seigneurie jusqu'en 1842 et de son fief Plaisance situé dans la seigneurie de la Petite-Nation, jusqu'à sa mort; il fut député de 1842 à 1847 , membre du Conseil exécutif et Commissaire des terres de la Couronne de 1844 à 1847 et, enfin, membre du bureau des Travaux publics de 1844 à 1846" (RAPQ pour 1951-1952 et 1952-1953, p. 167).

${ }^{41}$ "Marie-Rosalie Papineau (1788-1857), fille de Joseph Papineau, avait épousé Jean Dessaules en 1816" (RAPQ pour 1951-1952 et 1952-1953, p. 182).

${ }^{42}$ "Eugénie Papineau, fille d'André Papineau de Saint-Martin [en l'Isle Jésus], qui épousera le Dr Thomas Bouthillier de Saint-Hyacinthe [Maska]» (RAPQ pour 1951-1952 et 1952-1953, p. 228).

${ }_{43}$ «André Papineau (1765-1832), frère de Joseph Papineau, était tonnelier et 
Bouthiller de Maska a amené Eugenie et ont été tous les quatre a St Martin demander a marier Le dit docteur avec Eugenie; André a dabord fait bien des difficultés par consideration pour sa fille ainée, sa fille cherie Adelaïde qui devoit passer La premiere a peine de danser en semelles de bas; mais Reflexion faite on a dit que Le missionaire etoit a la Petite Nation et qu'elle pouvoit se marier La premiere si elle vouloit; il ne manque pas de marieux et pour ne pas prejudicier a son droit d'ainesse, Le docteur et Eugenie ont consentie bon gré mal gré a différer leur mariage jusques au vingt cinq du courant jour auquel ils feront Le sault de La carpe; Adelaïde a Le tems de le faire aussi et d'avance si elle Refuse elle [mot raturé] musera, et si La Dessaules peut, après les nôces faites, aller a la Petite Nation; je l'y accompagneray et Adelaïde dansera un Rigaudon en semelle de bas, je le lui promets.

Cette demande en mariage avait dû avoir lieu quelques jours ou quelques semaines auparavant, tout probablement entre Noël et le jour de l'An, puisque cette missive du 10 janvier 1826 fut précédée d'une brève note d'affaires du 5 janvier ${ }^{44}$ et que la dernière lettre donnant des nouvelles de la famille remontait au 19 décembre 1825: aucune allusion à ce mariage n'y était faite ${ }^{45}$.

On y lit qu'André Papineau hésite à consentir au mariage de sa cadette Eugénie "par considération pour sa fille aînée», Adélaïde, qu'il ne veut pas humilier. Des négociations ont alors lieu et les futurs mariés acceptent «bon gré, mal gré» de «différer leur mariage jusques au vingt-cinq du courant jour», soit le 25 janvier, ce qui semble bien peu aux yeux d'aujourd'hui. Si la grande demande avait eu lieu entre le 25 décembre et le 5 janvier et qu'ils comptaient s'épouser une semaine ou deux plus tard, supposons entre le $1^{\text {er }}$ et le 15 janvier, les épousailles n'auraient été reportées que de deux à quatre semaines environ. On remarque tout de même que le respect du droit d'aînesse taxait d'une contrainte bien réelle la décision du jeune couple, ce que

cultivateur à Saint-Martin sur l'île Jésus» (RAPQ pour 1951-1952 et 19521953, p. 223).

${ }^{44}$ RAPQ, op. cit., p. 227.

${ }^{45}$ Ibid., pp. 225-227. 
révèle précisément l'expression «bon gré, mal gré» qualifiant leur consentement et ce qui cause d'ailleurs les soucis et "difficultés» du père. D'autre part, l'obligation imposée à l'aînée de se marier la première «à peine de danser en semelles de bas" est aussi suffisamment sérieuse pour faire hésiter le père. Enfin, la promesse de Joseph Papineau d'accompagner sa fille, Marie-Rosalie Papineau-Dessaules, à la Petite-Nation, "après les noces faites" et d'enclencher le processus qui fera qu' «Adélaïde dansera un rigaudon en semelles de bas» expliquerait le sens de la proposition «et d'avance si elle refuse, elle musera [. . ] je le lui promets». Tous ces éléments, qui accusent l'autorité de la tradition, portent à croire que ce rituel n'était pas une nouveauté dans la famille Papineau, mais qu'il était, tout au contraire, déjà bien établi. Pour qu'il ait pu jouir d'une pareille emprise, on peut présumer que les frères Papineau, tant l'épistolier Joseph qu'André, le père d'Eugénie et d'Adélaïde, en avaient été régulièrement témoins depuis leur jeunesse, entre les années 1765 et 1775 , et qu'ils devaient le considérer comme inévitable.

Pourtant, cette intéressante lettre laisse aussi plusieurs questions dans l'ombre: Adélaïde a-t-elle véritablement dansé en semelles de bas aux noces de sa sœur? Si oui, de bon gré le jour même ou de force "après les noces faites", à l'instigation de Joseph Papineau? Il est toutefois certain que le report du mariage d'Eugénie n'aura rien corrigé à la situation puisqu'Adélaïde était toujours célibataire le jour du mariage de sa sœur Marie (née en 1807) avec Narcisse Prévost, comme elle l'était encore quand son frère André (né en 1809) épousa Hermine Provencher. En fait, elle ne se mariera jamais. Si la coutume avait été rigoureusement appliquée dans la famille Papineau, Adélaïde aurait done dansé au total trois fois. L'a-t-elle fait? En outre, le silence de Joseph Papineau à propos de son fils Toussaint-Victor (1798-1869), qui ne se maria jamais, car il avait été ordonné prêtre en 1823 , ferait voir une limite à la sanction 
dans le cas d'une forme consacrée de célibat, celle qui exclut définitivement du marché matrimonial ${ }^{46}$. Ces interrogations, que la généalogie permet de formuler, resteront pour le moment un mystère, car la correspondance de Joseph Papineau n'en dit $\mathrm{mot}^{47}$.

Mais quelles étaient les modalités de ce rituel que Micheline Lachance, l'auteur du Roman de Julie Papineau - qui, le transposant, l'applique plutôt à Victoire, la sœur de Joseph Papineau restée vieille fille - , résume ainsi: «À ton âge, tu peux toujours danser le rigodon en semelles de bas, le sort en est jeté ${ }^{48}$ "? C'est la tradition actuelle qu'il faut interroger.

\section{II - LA TRADITION FRANCO-ONTARIENNE}

A. «DANSER SUR SES baS" EN ONTARIO fRANÇAIS

Tout récemment, nous avons relevé de nombreuses attestations de ce rituel (TABLEAU 1), qui s'avère très vivant dans certaines régions de l'Ontario où il se déploie en des variantes formelles bien caractérisées. La description synthétique suivante donne une assez juste idée de cette coutume.

En Ontario, la population française observe, de façon générale dans le Nord-Est, une coutume qui sanctionne l'aîné, frère ou sœur, qui s'est laissé devancer par son cadet, ou sa cadette, dans le mariage.

${ }^{46}$ RAPQ pour 1951-1952 et 1952-1953, p. 193.

47 Fernand Ouellet, qui nous a indiqué ces possibilités, propose d'autres questions sans réponse: "Dans la famille de Louis-Joseph Papineau, ses enfants Amédée et Azélie se sont mariés dans l'ordre, mais Ezilda, l'aûnée des deux filles, est restée célibataire. A-t-elle dansé en semelles de bas? Dans la famille de Pierre Bruneau, du côté de son épouse, sur sept mariages possibles, cinq eurent lieu; le deuxième fils, Olivier, est devenu prêtre, et l'avant-dernier de la famille, Théophile, est resté célibataire. A-t-il dansé en semelles de bas lors du mariage de sa cadette Rosalie en 1830?»

${ }^{48}$ Micheline Lachance, Le Roman de Julie Papineau. La Tourmente, Montréal, Éditions Québec Amérique, [1995], réimpression 1998, chapitre XIV «La Petite-Nation", p. 185. Nous sommes reconnaissant à cet auteur d'avoir bien voulu nous aider à retrouver le texte original qui lui avait inspiré ce passage. 
Ce rituel se déroule aujourd'hui le jour des noces du cadet, après le banquet, et ordinairement au cours de la danse qui suit. Au moment opportun, on invite l'aîné à se présenter au centre de la salle; s'étant assis sur une chaise, il ôte ses souliers et relève ses jambes de pantalon. Son cadet, ou une autre personne de sa parenté immédiate, lui enfile jusqu'à la hauteur des genoux des bas multicolores, où la couleur rouge domine régulièrement, le plus souvent en laine, parfois dépareillés, mais confectionnés par un membre de la famille expressément pour la circonstance; on a pu également les décorer de grelots, de pompons, de rubans, de plumes ou autres ornements propres à les rendre voyants et ridicules.

L'aîné se lève et exécute alors sa danse, en solitaire, sur un air bien rythmé, de préférence un rigodon. Le manège peut durer une dizaine de minutes environ pendant lesquelles les assistants, faisant cercle autour du danseur, l'encouragent, lui adressent des plaisanteries et, selon le cas, lancent par terre des billets de banque et des pièces de monnaie. Parfois d'autres invités viennent se joindre à l'aîné pour effectuer, isolément, quelques pas de danse; parfois, ils se relaient pour le faire tournoyer sur place, et ainsi l'étourdir tout à fait. À la fin du rituel, qui se passe dans la plus complète bonne humeur, on recueille l'argent jonchant le parquet - dont la somme va de quelques dizaines à plusieurs centaines de dollars selon la taille de la noce - et on le remet aux nouveaux mariés. L'aîné retire ses bas et les conserve en souvenir.

S'il y a plus d'un aîné, on les fait danser en même temps. Il peut arriver qu'un célibataire endurci danse à plusieurs noces; l'un d'eux a même dansé sept fois avant de se marier. Sans être absolument obligatoire, cette coutume est perçue comme telle et celui qui refuse de s'y prêter se le fera reprocher par des propos railleurs, par une mystification ou par une autre sanction. 
TABLEAU 1

Dénombrement et distribution par régions

des témoignages franco-ontariens

sur la danse rituelle de l'aîné célibataire

\begin{tabular}{llrr}
\hline Régions & & 1 & témoins \\
Est & Ottawa & 31 & \\
& Prescott-Russell & 5 & 37 \\
& Cornwall & 20 & 20 \\
Centre & & 4 & 4 \\
Sud-Ouest & & 4 & \\
Nord-Est & Algoma & 3 & \\
& Témiscamingue & 15 & 119 \\
& Nipissingue & 39 & 0 \\
& Cochrane & 58 & 180 \\
\hline \multirow{2}{*}{ Nord-Ouest } & Sudbury & & \\
Total & & & \\
\hline
\end{tabular}

Ce portrait contemporain présente bien, un siècle et trois quarts plus tard, la nature de la tradition suggérée par les propos de Joseph Papineau. Elle va même bien au delà en spécifiant le jour et le moment fixés pour l'accomplissement du rituel, sa mise en scène et sa durée, l'aspect des bas ou chaussettes, le type de danse et de musique approprié, de même que l'attitude des spectateurs. On peut supposer que bien des détails courants de nos jours peuvent différer de la tradition du XIX ${ }^{\mathrm{e}}$ siècle - comme le moment de la danse, la couleur et l'ornementation des bas, ou le lancement de pièces de monnaie qui ont pu varier et se fixer plus tardivement - mais le scénario global et la causalité profonde du rituel demeurent inchangés.

\section{La danse sur les bas}

Les nombreuses attestations franco-ontariennes de ce rituel, très vivant dans le Nord et l'Est, mais connu aussi dans le Centre et le Sud-Ouest, décrivent une tradition au moins centenaire, parfois pratiquée de façon similaire; 
mais, par suite d'une évolution dynamique, elle comporte aussi des variantes formelles renouvelées ou particulières, tout en retenant des formes anciennes qui furent peut-être jadis plus répandues encore.

\section{Terminologie}

«Danser sur ses bas», ou sa variante «danser sur les bas», est de loin l'appellation la plus courante pour désigner cette tradition partout en Ontario; régionalement, on dira "danser en pieds de bas" à Hearst où cette expression domine, mais on la connaît ailleurs aussi, surtout dans la région de Cochrane, à Hallébourg, à Kapuskasing et à Timmins, dans la région de Sudbury, à Hanmer et à Chapleau, et dans l'Est, à Rockland; on la trouve même une fois écrite «à pied de bas», à Port-Colborne, dans le Centre. On relève encore les variations "danse des bas" et "danse dans ses bas» à Sudbury, «danse en bas» à Sturgeon-Falls, et "danse en bas jaunes" à Welland (et à Rouyn, Québec). Dans le Nipissingue, on dit en outre "danser sur les chaussons» à Verner, à Sturgeon-Falls et à River-Valley, tout comme à Noëlville, dans le grand Sudbury, ou «danser sur ses chaussons» à Warren (Sudbury), à Kapuskasing et à Moonbeam (Cochrane). Qu'on les appelle «bas» ou "chaussons», il faut comprendre qu'il est ici question de chaussettes, c'està-dire d'un vêtement de pied qui s'arrête à la hauteur du mollet. Enfin, à Vankleek-Hill dans l'Est, on a noté «danser le vieux garçon», comme on parle à Hallébourg, Cochrane, de la «danse des vieux garçons».

\section{Raison d'être}

Partout, cette pratique vise à mettre en évidence l'aîné non encore marié. C'est bien sûr une amende honorable à payer par le célibataire qui brise l'ordre normal du mariage, de l'aîné au cadet. Comme cette danse est déjà en soi humiliante, on ne désire pas en rajouter. Aussi, insiste-t-on généralement pour dire qu'on apprécie beaucoup le divertissement que procure ce rituel au mariage, la bonne 
humeur qui s'en dégage, la couleur qu'il apporte, la créativité des organisateurs et, combien plus, la réaction de la victime. Plusieurs indiquent que la contribution monétaire qui s'ensuit, au profit des nouveaux mariés, est une motivation additionnelle qui favorise le maintien de la tradition. Enfin, l'exposition de l'aîné, qui se singularise ainsi en dansant, est généralement perçue comme une révélation de sa disponibilité, ce qui, pour les invités célibataires de l'autre famille engagée dans le mariage, constitue un attrait supplémentaire.

Mais, dans les familles où il est à l'honneur, ce rite de passage conserve sur tout le territoire son caractère obligatoire: en aucun cas, l'aîné célibataire ne peut normalement s'y dérober, sinon gare à lui. Vers 1975, une jeune femme qui avait voulu rompre avec la tradition reçut une sanction pire: elle fut en effet pourchassée pendant de longues minutes par un ami qui la menaçait avec une vieille vadrouille sale et bien mouillée; comme elle craignait que les coups de vadrouille, que tentait de lui asséner aux pieds son poursuivant, ne finissent par salir et détremper complètement ses bas, ou ses autres vêtements, elle dut sautiller fréquemment pour l'éviter, au grand amusement des noceurs ${ }^{49}$. Dans les années 1980, une autre demoiselle, s'étant montrée fort offusquée, refusa catégoriquement d'accomplir cette danse; on n'insista pas, mais, à 21 ans, elle fut traitée de «vieille fille». Enfin, à Hawkesbury, à la même époque, un danseur ayant trop obstinément résisté à ce rituel incontournable, il se vit forcé de s'exécuter dans ses bas troués. La communauté ne cherche pourtant pas à blesser et à humilier le fautif. Aussi, les familles s'arrangent-elles pour ne pas indisposer le célibataire tout en s'assurant de sa collaboration. À Sudbury, s'il s'agit d'une personne timide, on l'encouragera en lui payant à boire «pour la dégêner» de sorte que, le moment venu, elle acceptera. Un autre témoin confirmera ce fait à Hearst: «Si

${ }^{49}$ Témoignage de M. Gaétan Gervais, confirmé le 26 mars 2001. 
la personne est un peu gênée, ils vont attendre qu'elle soit "chaude" un petit peu, mais pas trop longtemps pour éviter qu'elle danse à quatre pattes!» C'est ainsi que «l'oncle et le frère aîné, qui "s'étaient tous deux fait faire la barbe", ont dansé en même temps ${ }^{50}$ \%. Mais, dans d'autres familles de Sudbury, plusieurs ont affirmé qu'on se saisit carrément de l'aîné récalcitrant et qu'on l'oblige à danser. N'échappe pas à la règle qui veut. Et la règle se fait parfois inflexible. À Hawkesbury, un témoin divorcé a dû exécuter sa danse puisque, n'étant plus marié, il retombait dans la catégorie des célibataires. Selon un témoin de Tecumseh, un frère jumeau, aîné de quelques minutes du marié, dut aussi se soumettre au rituel à la fin des années 1980. Ailleurs, à Hearst, en 1995, à cause du remariage de sa mère, une cadette célibataire consentit à danser sur ses bas, étant donné qu'elle était plus vieille que la mariée de sa bellefamille. Encore, à Timmins, en mars 1998, la sœur de la mariée et sa mère ayant chaussé leurs bas, un témoin demanda aussitôt à son compagnon ce que la mère faisait là; sans broncher, celui-ci lui expliqua que la mère de la mariée ne s'était elle-même jamais mariée et qu'elle devait danser comme les autres ${ }^{51}$. Ainsi, mieux vaut se plier à la tradition, qui impose une contrainte bien réelle, mais connue, que de se voir infliger une peine plus cruelle encore. .

L'aîné qui danse

L'aîné est en principe le seul à danser. Mais, dans certaines familles, il y a parfois plusieurs aînés: à Windsor, on en a signalé sept en 1990, mais on compta huit frères à Hawkesbury qui ont dansé dans les années 1940 aux noces de leurs quatre sœurs. On pourra tantôt les faire danser tous en même temps, tantôt les faire entrer à tour de rôle. On a vu des personnes de sexe opposé, de la famille d'un ou des deux conjoints, danser temporairement en couple.

${ }^{50}$ Vicky Ayotte, le 24 février 1999.

${ }^{51}$ Cindy Grzela, 1999. 
Mais la tradition exige qu'ils dansent le plus longtemps en solitaire. On note occasionnellement des exceptions, comme le rapportait un informateur de Blezard-Valley, à propos de sa vieille tante célibataire, Élodie Bélisle, qui dansa sur ses bas, à partir des années 1920, à tous les mariages de ses frères et sœurs; elle portait des bas de laine ordinaires et quelqu'un de la famille la faisait valser après le souper de la noce ${ }^{52}$. Des célibataires ont dansé trois fois, cinq fois, ou plus: «Mon oncle se mariera cette année, nous confiait une étudiante de Saint-Charles; comme il est l'aîné de la famille, cela signifie qu'il a dansé sept fois sur ses bas ${ }^{53}$." Qui dit mieux? À Verner, entre 1958 et 1970, la sœur célibataire d'un témoin «dut danser sur ses chaussons de laine quatorze fois; en dernier, dit-on, elle tricotait ellemême ses bas". À Kapuskasing, en décembre 1977, un vieil oncle de Hull et une vieille tante de Fauquier célibataires ont dansé sur leurs bas. Il n'y a donc pas de congé en raison de l'âge qui rendrait le rituel prescriptible, ni du nombre de fois où on l'a accompli. Toutefois, dans les années 1960 , à North-Bay, un futur prêtre bénéficia d'une dispense en raison de sa vocation religieuse. À Hawkesbury, à la même époque, on lança par plaisanterie à un danseur: "T'as pas voulu faire un curé: danse sur tes bas! $!^{54}$ », montrant bien que, là aussi, la prêtrise mettait à l'abri du rituel. À Sudbury, en 1996, au dernier mariage d'une famille, tous les frères et sœurs de la mariée ont voulu danser, pour bien marquer que ce rituel avait fini de s'accomplir au sein de cette génération et qu'il devait désormais passer à la suivante.

Les bas

Entre les années 1920 et 1960 , tous les témoins affirment que l'aîné dansait sur des bas ordinaires. Il faut entendre par là qu'il s'agissait des chaussettes que le célibataire

\footnotetext{
${ }_{52}$ Abbé Léo Legault, le 26 juin 1999.

${ }^{53}$ Mélanie Roy, 1999.

${ }^{54}$ À rapprocher de l'expression "Tu n'as pas voulu faire un prêtre. . travaille!», qui avait cours dans les années 1950, selon Fernand Ouellet.
} 
portait pour l'occasion, des bas de toilette pour le garçon et des bas de nylon pour la fille. On signale aussi des bas de laine, très simples, la plupart du temps de couleur grise ou neutre; dans ce cas, l'aîné devait les revêtir avant de danser. Il semble encore que la préférence allait à des bas de travail plutôt qu'à des bas de toilette. Dans les années 1930, à Moose-Creek dans l'est ontarien, au mariage d'un témoin, sa sœur a dansé en bas de nylon. À Hawkesbury, à la même époque, on parle de bas de laine simples de couleur indécise. Un autre informateur, originaire d'Alfred, souligne que c'étaient de «vieux bas» que le danseur devait enfiler. À Port-Colborne, on a noté, vers 1948, des bas gris et rouge tricotés par la grand-mère, et à Chapleau, à la même époque, des «bas d'hiver de bûcheron». À SturgeonFalls, à Verner, à Lavigne, à Noëlville, à Sudbury et à Spanish, on relève encore des "bas ordinaires" et des "bas de nylon».

Après les années 1960, on assiste à une véritable évolution dans l'aspect des chaussettes. D'un côté, on maintiendra jusqu'à nos jours le port de bas ordinaires, en laine grise ou d'une couleur discrète, pour le garçon et de bas de nylon pour la fille dans quelques municipalités de l'Est (à Hawkesbury, à L'Orignal, à Plantagenet et à VankleekHill), du Centre (à Welland) et du Nord-Est (à Corbeil, à North-Bay et à Cache-Bay dans le Nipissingue; à Fauquier et à Timmins, où on précise "des bas de travail ordinaires gris et rouge", dans Cochrane; et à Wawa, "des bas de laine gris ordinaires", dans Algoma).

Mais la mode sera désormais à la couleur et à la décoration fantaisiste. En fait, il s'agit de rendre les bas voyants, ridicules et originaux le plus possible. On verra alors des bas courts et unis, blancs, jaunes, couleur de la jalousie, dit-on, rouges ou bruns, ou de couleur phosphorescente (jaunes dits «fluo" à Haileybury, Témiscamingue, orange «fluo» à Blezard-Valley et à Sudbury); tantôt, le bas gauche ne sera pas de la même couleur que le bas droit, l'un brun 
et l'autre rouge (Cochrane), ou l'un vert et l'autre rose (Hanmer, Sudbury); on verra parfois, quand il y a deux danseurs, que chacun porte un bas brun à droite et un bas rouge à gauche par exemple, une même paire de bas étant divisée entre eux deux. Puis, ailleurs, les mêmes couleurs se répétant dans les deux bas, les éléments d'une couleur du bas gauche seront d'une autre couleur dans le bas droit: le bout, le talon ou l'ouverture par exemple. Ensuite, les bas se font plus longs et recouvrent tout le genou; à Hearst, depuis la fin des années 1980, dans le cas où il y a plusieurs danseurs, les bas des plus âgés sont plus longs que ceux des plus jeunes. Multicolores, tricotés en anneaux plus ou moins larges, plus ou moins réguliers, et superposés, ils sont réputés avoir été confectionnés de «restants de laine». Ils sont aujourd'hui de loin les plus populaires et on les décrit comme étant barrés, rayés, en zigzag, et leurs couleurs vives, bariolées, "affreuses", "horribles", pour tout dire laides. Parfois, chaque orteil a son enveloppe, comme un gant, de couleur différente; on voit des bas torsadés en rouge et blanc; d'autres s'achèvent en pointe recourbée; d'autres, cousus dans du feutre, montent à mi-cuisse et s'évasent comme des bottes que le danseur est parfois forcé de retenir: vers 1995, dans le Nord-Est, on les avait décrits comme des "bas de style lutin rouge et vert». D'autres bas sont parfois de véritables pantoufles, comme ces chaussures commerciales en forme de "hot dog», garnies de condoms à leur extrémité, rencontrées à Kapuskasing et à Fauquier. Certains de ces bas ont l'allure de mocassins, ou de bottes sauvages. Divers motifs et dessins y figurent aussi: une vache signalant le métier d'un aîné cultivateur (Haileybury, Témiscamingue), les initiales du danseur (Hearst, 1995) ou la date de la noce (Sudbury, 1996). S'il n'y a pas de couleur obligatoire - la couleur des robes des filles d'honneur détermine parfois celle des bas, mauve, crème, sarcelle, etc. -, le rouge revient souvent, avec des tons de bleu, de blanc, d'orange et de noir. $\grave{A}$ 
Timmins, dans les années 1990, on choisit des couleurs féminines, des tons pastel, pour les hommes.

Le bas lui-même, simple ou multicolore, s'épanouira par une ornementation recherchée: grelots, clochettes, sonnettes ou autre décoration bruyante, petits ou gros pompons, glands, petits boutons, boucles, guirlandes, fils ou brins de ficelle, rubans, cordons, franges, plumes, condoms, brillants, petits objets appliqués, retailles, des yeux, un nez, fentes avec des yeux et des leurres de pêche, etc. En somme, tout est possible pourvu que le résultat soit extravagant et prête à la rigolade.

D'où viennent de tels bas? S'ils peuvent occasionnellement avoir été achetés en raison de leur allure singulière, de leurs couleurs affreuses, de leur originalité, ils sont le plus souvent de confection domestique. Il revient à la famille de l'aîné de les prévoir. Tricotés ou cousus à la main par une femme, la mariée elle-même, sa sœur, sa mère ou sa grand-mère, ce sont des pièces uniques que quelques intimes seulement ont vues avant la cérémonie. Aussi, les bas seront-ils conservés en souvenir par le couple marié ou par la personne qui les a confectionnés, ou le plus souvent laissés au célibataire qui les a utilisés. Dans ce cas, il en fera l'usage qu'il voudra, les portant pour des travaux domestiques jusqu'à leur complète usure, les oubliant parmi ses affaires, les jetant tout simplement ou, très rarement, les conservant pour la prochaine fois; bien que cette dernière possibilité soit rare, elle s'est rencontrée chez un témoin qui dansa plusieurs fois avec son frère à Hawkesbury, dans les années 1930, avec les mêmes bas, et tout récemment chez un autre à Hearst qui dut danser à deux noces rapprochées. . Il est exceptionnel qu'on les emploie pour une autre personne. À Sturgeon-Falls, le danseur portait ses bas à une réception le lendemain des noces au début des années 1990. 
Autres pièces de vêtement

Le danseur n'est pas tenu de porter un vêtement spécial autre que les bas décrits précédemment pour accomplir sa danse rituelle. Cependant, on peut lui imposer le port d'une autre pièce de vêtement selon l'humeur des organisateurs et les circonstances. Un témoin de Sturgeon-Falls a vu un rituel à Amos (Québec), entre 1989 et 1999, où le célibataire portait un bonnet. À Sudbury, en 1995, un danseur a dû porter "une magnifique tuque ornée de grelots" ainsi qu' «une ceinture de grelots»; à des noces célébrées le 26 décembre 1998 à Moonbeam, l'aîné dut de même coiffer "la tuque du père Noël». Exceptionnellement, on a vu un tutu de ballerine à Hawkesbury dans les années 1980 ou une écharpe portée à la ceinture à Sudbury, entre 1980 et 1990. À Rockland, en 1995, on assista à une véritable mise en scène où le danseur et quatre autres personnes importantes pour les mariés ont dansé, déguisés en Indien, en policier, en motard, en ouvrier et en cow-boy, à la façon du groupe de chanteurs anglophones Village People. Dans un autre cas, au même endroit, le danseur portait des caleçons, dits "boxeurs", à pois bleus et une casquette à hélice; on signale aussi des caleçons "drôles" dans le Nord, entre 1975 et 1995, et, à Hearst, dans les années 1980, des "combines", sous-vêtements longs. À Hearst encore, quinze ans plus tard, un groupe de danseurs, après l'annonce, "sortirent des coulisses vêtus de pantalons courts rouges et d'un tee-shirt blanc [et] portant des verres fumés». Plusieurs témoins parlent encore de déguisement ou de costume comique à Noëlville, entre 1980 et 1995, d'un chapeau melon et de «sous-vêtements drôles». À Blezard-Valley, en 1990 , on fit porter des bottes de caoutchouc à une victime originaire de Terre-Neuve et une grosse cloche à vache; en 1996, à Cache-Bay, on fit chausser à la victime des bottes semblables pour danser sur une musique difficile à suivre avant de passer au véritable rituel des bas; un témoin de Sudbury a vu un danseur chausser des raquettes à neige à 
Gallichan, Québec. En 1995, «[m]on cousin a porté au cou une cloche à vache", affirme un informateur de Sudbury.

Outre ses souliers, qu'il doit obligatoirement oter, et parfois son veston qu'il peut enlever pour se mettre plus à l'aise, le danseur exécute son rituel dans son costume de fête. Parfois, on l'invite à se dévêtir davantage: à L'Orignal, en 1995, le danseur devait retirer une pièce de vêtement si les gens lui lançaient de l'argent (cravate, etc.); à Noëlville, les gens paient parfois pour que le danseur retire un vêtement. À Garson, en 1997, on a remarqué que le danseur ne portait qu'un bas pour danser; l'autre circulait entre les invités, probablement pour y recueillir les offrandes en argent.

\section{Le moment choisi}

Le moment retenu pour l'exécution du rituel ne varie guère d'un endroit à l'autre. C'est toujours au cours du bal qui suit le banquet de noce, dans la soirée donc, et après que toutes les cérémonies honorant les nouveaux mariés se soient déroulées, comme le lancement du bouquet de la mariée et le lancement de la jarretière.

Le déroulement du rituel

Au moment convenu, l'animateur interrompt la danse pour attirer l'attention des invités. Une annonce brève révèle alors que l'un des conjoints a un aîné qui est toujours célibataire et qui devra accomplir la sanction rituelle. Ses amis et parents tournent vers lui leurs regards et l'encouragent en lui ouvrant le passage. Normalement, il s'avance dès qu'on le nomme. Une fois rendu au centre de la salle, ou près de l'animateur, on lui présente les bas, quelquefois en mentionnant le nom de la personne qui les a fabriqués. C'est couramment cette dernière qui les sort de son sac à main où elle les tenait cachés depuis le début, comme on l'a remarqué à Sudbury, à Timmins, et même à Gatineau, Québec, entre 1960 et 2000. À Ottawa, en 1999, 
on les a apportés sur un plateau. On les montre à tous. Selon la disposition de la salle, l'aîné s'assoit sur la chaise qu'on lui a expressément avancée, sur les marches de la scène ou carrément par terre. Souvent, il doit chausser luimême ses bas pendant que tous s'approchent pour mieux voir. Mais très souvent aussi, c'est son frère ou sa sœur qui les lui enfile. «Le fait que c'est le cadet nouvellement marié qui présente les bas à son aîné accentue davantage le fait qu'il s'est laissé devancer par le plus jeune ${ }^{55}$.» Parfois, c'est sa mère qui pose ce geste. Ensuite, l'aîné célibataire roule ses pantalons ou relève sa robe et, debout au centre, montre à tous les invités les bas qu'on lui a faits. Les caméras immortalisent la pose. Puis on attend le signal de la danse.

Il arrive que l'aîné ait déjà revêtu ses bas au moment de l'annonce. Dans ce cas, les préparatifs se seront déroulés en privé dans une petite chambre attenante à la salle de réception ou directement à la place qu'occupe l'aîné. Il peut agir ainsi pour montrer sa bonne volonté ou parce que la tradition lui impose de se munir des bas appropriés, des bas rouges par exemple dans le Témiscamingue à la fin des années 1970 ou des bas colorés avec orteils séparés achetés par le danseur à Hawkesbury vers 1975. Dans la région de Sudbury, à Val-Caron et à Chelmsford, l'aîné devait dans certaines familles confectionner lui-même ses bas; mais parfois cette obligation ne concernait que la fille qui devait savoir tricoter.

\section{La danse}

Alors que les noces se déroulaient rarement à l'extérieur de la maison des parents des mariés avant les années 1960, elles ont maintenant presque toujours lieu dans une salle communautaire ou commerciale. C'est donc là aussi qu'a lieu la danse de l'aîné célibataire.

Si le joueur de violon n'est plus toujours de la partie, comme dans les noces à la maison, la musique demeure

${ }^{55}$ Estelle Corriveau, 2000. 
vive et entraînante, qu'elle soit produite par un musicien, par un orchestre ou par des disques. Généralement, on joue un rigodon traditionnel ou une pièce musicale contemporaine de même type. Le choix de celle-ci revient tantôt au cadet marié, tantôt à l'aîné qui danse (Hawkesbury, Sturgeon-Falls, Chelmsford), tantôt au musicien ou à l'animateur. Aujourd'hui, on trouve même des chansons populaires de toute nature, «la Danse des canards" par exemple à Welland et à Sudbury, pas toujours en français, mais ordinairement enlevantes. Dès les premières mesures, le danseur s'exécute. Seul, devant tous, il gigue, c'est-à-dire qu'il sautille et se balance au rythme de la musique, levant un pied puis l'autre, agitant les bras vers le haut puis vers le bas, marchant en cadence de façon réservée ou énergiquement comme un gymnaste, tantôt avançant, tantôt reculant, parfois pivotant sur lui-même, il décrit un cercle en se concentrant sur sa danse, mais en souriant et en réagissant de bonne grâce aux propos qui lui parviennent. À Val-Thérèse, pendant la décennie 1980-1990, on en a vu un qui dansait avec sa chaise. Quand on a jugé que l'aîné a bien rempli son rôle, son cadet nouvellement marié s'avance et exécute quelques pas de gigue autour de lui. Puis le conjoint peut faire de même et d'autres personnes, comme l'amie de cour de l'aîné, à tour de rôle cependant, par sympathie, mais jamais pour lui voler la vedette. Parfois, les parents et amis se relaient et le font tournoyer sans arrêt par un crochet de bras de sorte que l'aîné en est complètement étourdi et qu'on a alors fort à faire pour le maintenir en équilibre.

Ce manège dure le temps d'une longue chanson, de cinq à dix minutes environ, mais parfois plus: dans l'Est, le temps de quelques chansons à Lefaivre, en 2000; à CacheBay, deux chansons furent jugées trop longues au milieu des années 1980; mais on a noté de cinq à six chansons en 1990 à Hawkesbury. Dans les années 1940, à Hawkesbury, la danse aurait duré trois quarts d'heure dans un cas et, 
dans un autre, un groupe de huit danseurs, tous frères, aurait dansé dans le salon de la noce sur un air de violon depuis $17 \mathrm{~h}$ jusqu'à $22 \mathrm{~h} 30$. À Chute-à-Blondeau, en 1978, l'un des danseurs a retiré ses bas et dansé nu-pieds; cet événement est exceptionnel et il semble que la chaleur accablante en soit la cause, car on avait pris soin de distribuer aux invités des serviettes de papier pour éponger le visage du danseur. Si la durée de la danse n'a rien à voir avec la différence d'âge entre l'aîné et son cadet, le nombre des danseurs peut évidemment la rallonger, car on tient à photographier à plusieurs reprises tous les danseurs. À Hearst, on a introduit une nouveauté depuis le milieu des années 1980: on défait une botte ou meule de foin, qu'on étend par terre, et sur lequel danse l'aîné.

\section{Les spectateurs}

On aura compris que les spectateurs quittent ordinairement leur place et se disposent en cercle autour du danseur de façon à ce que tous puissent bien le voir. Debout, ils l'encouragent en tapant des mains et en se balançant au rythme de la musique. Plusieurs lancent des plaisanteries relatives à son état de célibataire pour s'en moquer: «T'as l'air fin en crisse, là, hein!» À Kapuskasing, on lance parfois des condoms au danseur, des fleurs à Verner. Certains proches participeront aussi à la danse comme on l'a déjà indiqué.

Depuis les années 1960, un nouvel élément s'est ajouté au rituel. On lance désormais de l'argent au danseur. $\mathrm{Ce}$ furent d'abord des sous noirs qu'on jetait à l'aîné en guise de raillerie et avec le plaisir anticipé de le voir se pencher à la fin du rituel afin de ramasser une à une les pièces tombées par terre; on a noté ce fait à Sudbury et à SturgeonFalls. Selon un témoin de Whitefish et de Sudbury, certains auraient même souhaité que le danseur glissât sur les sous: "cette collecte sous-entendait que l'aîné pourrait 
«DANSER SUR SES BaS». RÉmANEnce D'UNe SANCTION POPULAIRE

"s'acheter" un conjoint avec la somme recueillie ${ }^{56}$ ». Ainsi, quand on lance des sous, c'est habituellement pour se moquer de l'aîné; la somme qu'il recueille est d'ailleurs dérisoire, ne dépassant jamais quelques dollars.

Mais, de plus en plus, on s'est mis à lancer de l'argent de papier, des billets d'un ou de deux dollars (aujourd'hui remplacés par des pièces de monnaie), des cinq, des dix, des vingt, et plus encore:

Ma grand-mère me disait, écrit une jeune étudiante, qu'autrefois les gens lançaient des trente sous [0,25 cents], mais de nos jours je peux vous dire que les gens deviennent de plus en plus généreux. Aux noces de ma cousine, l'an dernier, son frère a dû danser sur ses bas et les gens jetaient des billets de $5 \$$, de $10 \$$, de $20 \$$ et, croyez-le ou non, j'ai même vu un billet de $50 \${ }^{57}$.

À Hallébourg, un informateur renchérit: «J'ai même vu un $100 \$$ par terre.» À Sudbury, on note aussi: «De nos jours, les spectateurs lancent de l'argent par terre, dans le but d'encourager le danseur et d'amasser des fonds pour payer la "chambre" des mariés le soir de leurs noces ${ }^{58}$." Car il n'est pas question de récompenser le danseur qu'on voulait sanctionner. S'il danse et que l'opération devient rentable, il ne gardera pas l'argent pour lui: c'est pour les nouveaux mariés. Si la somme ainsi réunie se limitait au départ à quelques dizaines de dollars, entre $50 \$$ et $80 \$$, elle est rarement inférieure à $100 \$$ de nos jours, atteignant régulièrement $200 \$$ et plus: on a déjà atteint $250 \$$ à Sturgeon-Falls, à Iroquois-Falls et à Val-Gagné, 300\$ à Noëlville, 500\$ à Sudbury et à Tecumseh. Il appartient tantôt au danseur de ramasser lui-même les pièces et les billets après la danse, tantôt aux demoiselles ou aux garçons d'honneur, qui, pendant la danse, pousseront vers le centre à l'aide d'un grand balai l'argent tombé, tantôt aux enfants, en particulier le page et la bouquetière, ou aux

\footnotetext{
${ }^{56}$ Annie Gagné, 2000.

${ }^{57}$ Mélanie Roy, 1999.

${ }^{58}$ Estelle Corriveau, 2000.
} 
mariés eux-mêmes. À Sudbury, on a vu une fois un bocal, déposé au milieu de la salle, qui était destiné à recevoir les offrandes. Dans tous les cas, l'argent sera remis aux mariés, mais sans toujours le compter auparavant ni annoncer le montant réuni. À Kirkland-Lake, c'est dans les bas du rituel qu'on dépose l'argent avant de le remettre aux nouveaux mariés.

Cette nouvelle pratique de jeter de l'argent, qu'on rencontre dans toutes les régions franco-ontariennes, n'est cependant pas encore répandue dans toutes les familles. Là où elle existe, elle remplace d'autres rituels de quête. À Cache-Bay, lorsqu'il n'y a personne qui danse sur ses bas, on met en scène une autre coutume: il s'agit d'une danse payante où, à tour de rôle, les hommes versent une contribution convenue pour danser avec la mariée et les femmes font de même avec le marié. À Sturgeon-Falls, on recueille de l'argent en passant le soulier de la mariée. Il est certain qu'on ne peut maintenir deux rituels de quête dans un même mariage sans encourir la réprobation populaire. Aussi, compte tenu de la popularité grandissante du lancement de l'argent au cours de la danse sur les bas, qui, selon certains témoins, se présenterait presqu'à chaque noce, il y a tout lieu de se demander si les autres types de quête pourront longtemps survivre.

Perçue comme une tradition canadienne-française par tous les informateurs, elle demeure obligatoire même dans les mariages mixtes et en dehors du lieu d'origine de la famille. C'est ainsi qu'elle apparaît parfois dans des noces italiennes, anglophones ou autres quand l'un des conjoints est franco-ontarien ou même dans des noces entre Canadiens français quand la famille d'un des conjoints ne la connaît pas; de même, on l'a vue pratiquée par des Franco-Ontariens à de nombreuses noces, à Vancouver, à Halifax, à Hamilton, comme en Californie. 


\section{La danse dans l'auge}

La «danse sur les bas», qui semble aujourd'hui générale et en pleine vitalité dans la plupart des régions de l'Ontario français, a connu d'autres formes toujours vivantes, quoique moins courantes et en régression, mais souvent plus humiliantes. La grande popularité de cette première forme du rituel est peut-être en voie d'occulter une variante qui semble tout aussi ancienne, mais devenue minoritaire, régionale et de moins en moins fréquente. Dans certains villages franco-ontariens, l'aîné devait autrefois accomplir ce rituel dans une auge à cochon et, naguère, dans une cuve servant au lavage. Il s'agit de la "danse dans l'auge», une tradition contemporaine tout de même attestée une quarantaine de fois.

Bien sûr, il s'agit toujours de sanctionner, par une danse publique, l'aîné célibataire le jour des noces de son cadet. Si donc la raison d'être du rituel, le choix de la victime et le mode d'exécution demeurent constants, quelques éléments varient.

Dans le sud-ouest ontarien, à Pointe-aux-Roches notamment, la «danse dans l'auge» est pratique courante et elle serait même la seule forme connue de ce rituel. D'apparence plus rurale, cette tradition a légèrement évolué au cours des dernières années. Selon le témoignage de M. Paul Tremblay recueilli par notre collègue Marcel Bénéteau en 1994, ce rituel était réservé aux garçons:

Danser dans l'auge, là, ça, c'est si que ton frère se mariait ton frère plus jeune que toi -, il se mariait avant toi, toi, tu dansais dans l'auge. Et puis les gars ressoudaient avec [. . ] les vieilles auges sales, hein, ils allaient voler ça dans aucune soue en quelque part. Le gars s'attendait jamais, hein, puis tout d'un coup tu trouvais cette maususse d'auge, hein. Les gars [disaient]: «Tu vas danser dans l'auge». [. . ] On fait encore ça, nous autres [à Pointe-aux-Roches] [. .] dans la famille des Tremblay. [. . .] Ils font faire des beaux petits auges [. . ] avec son nom dessus. [. .] Après ça, même tu peux danser avec eux autres [les aînés], eux autres restent dans l'auge, tu peux danser à l'entour. [. .] 
Dans mon temps, moi, dans une noce là, le gars qui était pris, il dansait tout seul en avant puis les autres riaient de lui. [. .] Avant le lunch, c'était une des dernières choses, ça là. Tu sais là parce que jamais ils voulaient lui laisser assavoir quand est-ce qu'il était pour se faire poigner, le gars. [. .] Ah, il s'en doutait, il s'en doutait. Mais des fois, il y en a qui pensaient: "Ils ont oublié.» Tu disais pas: "Aïe, as-tu emmené un[e] auge, hein, pour danser dans l'auge?».[. .] C'est une vieille tradition française, ça. [. .] C'est ça que c'est que c'était danser dans l'auge: quand quelqu'un plus jeune que toi se mariait dans ta famille. . [. .] toi, tu danses dans l'auge, mon homme. [. .] Mais c'était bien différent.

Aujourd'hui, ils [jousent?] ça à cause que c'est net là. Mais la fille, ç'aurait pas compté parce que les filles se mariaient plus jeunes que les gars. [. . ] Si c'était une fille qui se mariait plus jeune qu'une autre fille, là, ç'aurait été $O K$, la fille aurait dansé. [. .] La grosse affaire, c'était pour les gars.

C'était, si tu regardes en arrière, tu vas voir qu'il y avait beaucoup de gars de cultivateurs qui étaient campagnards; ils étaient peut-être bien [bagnards?] un peu [rires]. Ils voulaient pas se lâcher de rester à [la] maison, hein, puis tu pouvais pas emmener ça à nulle part. . [. . ] Tu sais. Ils étaient durs à déniaiser, ça. Parce que ce que c'était, le chose [l'intention], c'était pour essayer de. . "Ah! tu vas t'en trouver, une femme", tu sais. [Puis] encore, les gars, ils avaient peur d'aller. . Je pense qu'il y avait beaucoup de ça, là-dedans, qui a causé ça, je pense. C'est pour essayer. . Puis en même temps, ça annonçait aux autres autour, dans la salle,. . [qu'il y en avait un qui était pas marié encore] ouais, il est pas marié celui-là! Aïe! Voyez-vous, les filles, il y en a un qui est lousse icitte là [rires] parce que, vois-tu, tu mettais toujours deux familles, les familles sur l'autre bord, les filles sur l'autre côté, hein. "Qui est-ce que c'est, ce gars-là?» Pour les filles, hein. [Bien, ils se rencontraient aux noces puis. . ${ }^{59}$.

${ }^{59}$ Collection Marcel Bénéteau, entrevue enregistrée le 5 avril 1994 auprès de Paul Tremblay, né en 1933, de Pointe-aux-Roches, Ontario. L'enquêteur nous a gracieusement communiqué le document sonore et les extraits qu'il en a tirés pour une recherche intitulée «Les Rituels de mariage comme témoins d'identité culturelle: une enquête préliminaire auprès de deux communautés francophones du sud-ouest de l'Ontarion, un exercice préparé dans le cadre de ses études de maîtrise en ethnologie à l'université Laval en 1994 (pp. 13-15); transcription par J.-P. Pichette, 2 p. ms. Cette tradition serait inconnue à Rivière-aux-Canards, village qui appartient à une autre tradition. 
Ce même informateur nous confirma que la tradition s'est reproduite encore tout récemment, en février $2001^{60}$. Ainsi, on est passé d'une vieille auge sale à une auge propre et même neuve, construite et identifiée spécialement pour l'occasion. À Grande-Pointe, non loin de là, on a aussi signalé cette tradition vers 1988 .

\section{De l'auge à la cuve}

Néanmoins, c'est dans la région de Sudbury que la danse dans l'auge, et ses adaptations, semble le plus répandue. Au début des années 1950, on l'exécutait nu-pieds «dans un banc viré à l'envers", au dire d'un témoin de SaintCharles. Un autre affirme qu'elle se pratiquait dans l'auge, dans une cuve ou sur ses bas dans un banc à l'envers, entre les années 1940 et 1950, et qu'on ne lançait pas d'argent; on le réservait plutôt pour payer le violoneux. C'est ce que confirme une étudiante qui résume l'évolution de la tradition dans sa famille:

Mes grands-parents ont pris connaissance de cette tradition lorsqu'un des frères de mon grand-père s'est marié avant un de ses frères aînés, dans les années 1940 ou 1950 . Ma mère affirme qu'elle se rappelle de cette coutume durant les années 1960 quand un de ses frères avait dansé dans une auge à cochon. Auparavant, à Saint-Charles, les gens ne dansaient pas sur leurs bas, mais dansaient plutôt dans une auge à cochon ou dans une cuve de métal remplie d'eau. C'est ce que mon père a fait en 1972 ou 1973. Ce fut dans les années 1977-1978 qu'on a commencé la danse sur les bas ${ }^{61}$.

D'autres témoins de Saint-Charles parlent de la danse dans l'auge après les années 1990. Un informateur de Chapleau, originaire de Caraquet, a entendu dire que quelqu'un avait dansé "dans une auge à cheval» au NouveauBrunswick, vers la fin des années 1940. À Val-Thérèse, vers 1954, on dansait «dans une cuve». Entre 1979 et 1996,

${ }^{60}$ Témoignage de M. Paul Tremblay recueilli au cours d'une consultation téléphonique le 7 mai 2001.

${ }^{61}$ Mélanie Roy, 1999. 
une célibataire a dansé sept fois dans l'auge à Ottawa; il s'agissait de mettre un pied dans l'auge et de «sauter pardessus $^{62} »$. La famille, des cultivateurs d'origine irlandaise de Vinton et de Campbell's Bay au Québec, transportait l'auge à la salle de danse pour l'occasion. À Noëlville, on a pratiqué la danse dans l'auge ou dans une cuve: un témoin se rappelle y avoir vu un célibataire portant des «combines" [caleçons longs] rouges et, à Verner, une fille vêtue d'une robe ancienne avec bonnet et bas multicolores avec orteils séparés, danser dans une cuve de glace, entre 1960 et 1980. Plusieurs ont connu la danse dans une cuve contenant de la glace à Verner. À Spanish, entre 1932 et 1942 , la danse dans la cuve avait lieu dans la cuisine, entre le dîner et le souper. À Sudbury, on signale aussi la danse dans la cuve en 1942:

On peut aussi danser dans une cuve à lavage, me dit ma mère. Accompagné de ses deux sœurs, mon père a dansé sur ses bas dans une cuve en 1942 à Sudbury aux noces de sa sœur cadette. Le rituel a porté fruit car ils se sont mariés quelques mois plus tard. Ma tante se souvient de l'événement: "C'était pour le fun, pour rire des aînés non mariés!» Il a dansé avec ses sœurs dans une grosse cuve à lavage ${ }^{63}$.

Au même endroit, près de cinquante ans plus tard, entre 1985 et 1990 , on précise que le rituel s'effectue «dans une cuve ronde» remplie de glace. En 1995, une famille italienne aurait adopté la danse dans une cuve à l'occasion d'une noce qui l'unissait à une famille franco-ontarienne: l'aîné franco-ontarien dansa sur ses bas et l'aîné italien dansa nu-pieds dans une cuve à vin, remplie de glace et de raisins. En l'an 2000, on affirmait qu'il y avait même un hôtel de Sudbury qui conservait une auge pour la pratique de la danse dans l'auge, mais il n'a pu être identifié.

Dans le Nord-Est, au Témiscamingue, la tradition est attestée dans les années 1980 à Kirkland-Lake et à

\footnotetext{
${ }^{62}$ Peut-être s'agit-il de danser un pied dans l'auge et l'autre pied à l'extérieur.

${ }^{63}$ Estelle Corriveau, 2000.
} 
Virginiatown, où on dansait "dans l'enclos à cochons ou l'étable», nu-pieds ou avec ses bas. Dans le Nipissingue, on dansait "dans une cuve" à Mattawa au début des années 1940; à Sturgeon-Falls, la «danse dans l'auge» a été pratiquée en 1985, et le célibataire gardait ses souliers; un autre témoin de Sturgeon-Falls a vu ce rituel plusieurs fois à Amos, au Québec, entre 1989 et 1999. Dans la région de Cochrane, où la danse sur les bas est particulièrement florissante, la tradition de la danse dans l'auge n'aurait été attestée que par deux témoins, tous deux de Val-Gagné, près de Timmins, entre 1974 et 1978; en mai 1978 , on précisait qu'il s'agissait d'une "auge à cochon».

Cette tradition est aussi connue des témoins du Centre, mais ils l'ont vécue ailleurs: l'un dit avoir vu à Sudbury, dans le quartier du Moulin-à-Fleur, la danse «dans une cuve d'eau»; un autre parle de la danse "dans une auge à cochon", un rituel réservé aux hommes à Maniwaki (Québec), en 1948, où les aînés dansaient "dans une vraie auge» et devaient rester une heure en pieds de bas: «J'avais trouvé ça dégoûtant", avoue ce témoin; vers 1960-1965, on avait utilisé de gros bas de laine sales, puis, en 1995, on avait eu recours à un «semblant d'auge». Pour sa part, un informateur né à Gracefield, Québec, a été témoin de ce rituel à plusieurs reprises avant 1940, tant à Gracefield qu'à Maniwaki. Un autre témoin d'origine acadienne se rappelait qu'en 1976, à Paquetville, un célibataire, chaussé de bas ordinaires, avait dansé "dans une boîte de carton" une valse avec sa blonde où chacun n'avait qu'un seul pied dans la boîte. Là non plus, on ne lançait pas d'argent.

Dans l'Est, cette forme serait inexistante dans la région d'Ottawa-Carleton et peu fréquente dans Prescott-Russell: à Hawkesbury, dans les années 1930, un témoin a entendu parler de la cuve; le mari d'un autre témoin a dansé dans une cuve d'eau froide au début des années 1990; à SaintIsidore, l'oncle d'un troisième a dansé sur les bas dans une 
cuve d'eau froide en 1976. Cependant, dans StormontDundas-Glengarry, ce récipient concerne quatre des cinq témoignages recueillis, tous localisés à Cornwall: «danser dans la cuve» ou "danser dans la cuvette» serait là un rituel encore pratiqué entre 1989 et 1999; on y danse avec ses bas, ceux de sa tenue de mariage ou des bas tricotés en laine rouge et blanc; la cuve contient de l'eau et parfois de la glace. Généralement, cette pratique n'entraîne pas d'offrande d'argent.

\section{Une tradition mixte}

À côté de la «danse sur les bas» et de la "danse dans l'auge», il se trouve des rituels mixtes où ces deux éléments si caractéristiques coexistent et semblent bien intégrés. L'expérience répétée d'une collègue de Sudbury, $\mathrm{M}^{\text {me }}$ Lucie Beaupré, qui a donné la première description de la «danse dans l'auge» illustre pertinemment cette harmonisation des deux formes dans une même famille et les variations que le contexte commande.

Une des réjouissances très répandues en Ontario et qui accompagne souvent un mariage est celle de danser dans l'auge. La coutume veut que les frères et sœurs célibataires, plus âgés que les mariés, dansent "sur leurs bas" le soir des noces. Ces bas doivent être rouges (couleur très française au dire des anglophones). S'ils sont plusieurs, ils dansent ensemble. S'il n'y a qu'une victime, c'est là que le plaisir commence. Cette personne doit danser seule pendant plusieurs minutes au rythme d'une musique endiablée. Souvent une auge ou cuvette est apportée. À ce moment, la victime doit prendre place à l'intérieur et continuer à danser au grand plaisir des convives. Cette coutume a pour but d'amuser les invités, mais très souvent certaines victimes en profitent pour annoncer leur disponibilité.

Par deux fois, j'ai eu à me soumettre à cette coutume. La première fois, c'était à North-Cobalt, près de New-Liskeard, lors du mariage de mon frère en 1978. Comme ce dernier n'avait qu'un an de moins que moi, les convives ont été très gentils et je n'ai dansé que sur mes bas rouges. À Timmins, ma sœur cadette, de quatre ans plus jeune que moi, s'est mariée l'année suivante. 
Cette fois, la danse m'a paru interminable. J'ai dansé dans une cuve grise pendant quelques minutes et ensuite un de mes cousins est venu à ma rescousse; lui non plus n'était pas marié dans le temps. J'ai presque réussi à user les fameux bas rouges. Je les ai jetés - espérant qu'il n'y aurait pas de troisième fois ${ }^{64}$ !

D'après ces témoignages, c'est vraisemblablement la "danse dans l'auge» qui aurait précédé au début du $\mathrm{XX}^{\mathrm{e}}$ siècle, du moins en Ontario, la «danse dans la cuve», mais la "danse sur les bas» ne serait pas moins ancienne et lui ferait depuis longtemps concurrence. Si le lieu de la sanction n'est plus la maison de la noce, le déroulement du rituel, lui, n'a guère varié. On peut présumer que les invités, dont l'attitude tout juste suggérée par certains détails demeure la même, en profitent pour s'amuser aux dépens de la victime. La durée du rituel, qui pouvait s'étaler sur plusieurs heures, s'est stabilisée autour d'une dizaine de minutes et le moment de son exécution s'est fixé en soirée. Avec le recul de l'auge, qu'on trouvait autrefois couramment dans les campagnes même si parfois on la préférait nettoyée, mais qui sortait de l'usage, il fallut bien trouver un autre récipient. Certains persistèrent à en fabriquer une expressément pour l'occasion, mais on eut bientôt recours à une boîte de bois ou de carton, un banc renversé ou un autre contenant. La grande cuve à lavage, carrée ou ronde, en tôle galvanisée, objet d'usage domestique même dans les villes, la remplaça avantageusement puisque, légère, on pouvait la transporter facilement et, propre, elle allait contenir l'eau, la glace et tout ce qu'on aurait l'idée d'y ajouter pour rendre le rituel encore plus amusant. Mais, avec l'avènement des machines à laver ou laveuses électriques, la cuve a été reléguée aux oubliettes et s'est raréfiée. Aussi, les chaussettes ont-elles pris toute la place et sontelles devenues le centre de l'attraction: d'ordinaires qu'elles

${ }^{64}$ Collection Lucie Beaupré, ms. $n^{\circ} 14$. Version personnelle racontée le 30 janvier 1985 et complétée le 12 juillet 2001. Née en 1954 à Nédelec, Témiscamingue, au Québec, elle déménagea avec sa famille à Timmins, Cochrane, Ontario, en 1964, et elle réside à Sudbury depuis 1977. 
furent au départ, elles ont évolué au point de devenir ces objets voyants, ridicules et bien caractérisés qu'on connaît à présent. Dès ce moment, apparut le jet de pièces de monnaie, dans un premier temps des sous pour ridiculiser l'aîné sanctionné et, depuis une quinzaine d'années, des sommes plus considérables destinées aux nouveaux mariés. La domination de cette tradition est telle de nos jours que parmi les 163 informateurs interrogés, 155 ou $95 \%$ ont été témoins de la danse sur les bas, ce qui veut dire qu'elle est connue même dans les familles des 41 témoins qui ont assisté à la danse dans un récipient (auge, cuve ou autre). Seule, une minorité de 8 informateurs ou $5 \%$ ne connaîtrait que cette dernière pratique et n'aurait jamais entendu parler de la danse sur les bas, de loin la plus répandue.

TABLEAU 2

Fréquence des variantes franco-ontariennes de la danse rituelle de l'aîné célibataire selon les époques

\begin{tabular}{|c|c|c|c|c|c|c|}
\hline PÉRIODE & ORDINA & $\begin{array}{r}\text { BAS } \\
\text { ACHE }\end{array}$ & ORNÉS & & $\begin{array}{l}\text { CIPIE } \\
\text { CuvE }\end{array}$ & I \\
\hline $1920-1944$ & 15 & 1 & 2 & 1 & 5 & 1 (banc) \\
\hline $1945-1959$ & 3 & 1 & 5 & 3 & 2 & 2 (banc) \\
\hline $1960-1979$ & 9 & 7 & 21 & 4 & 3 & 1 (boîte) \\
\hline $1980-2001$ & 14 & 14 & 89 & 5 & 13 & 1 (enclos) \\
\hline Total & 41 & 23 & 117 & 13 & 23 & 5 \\
\hline Grand total & & 181 & & & 41 & $=222^{*}$ \\
\hline
\end{tabular}

* Ce tableau a été établi à partir des 163 témoins dont le témoignage était complet sur les 180 réunis. Toutefois, ces informateurs ont assisté à plusieurs mariages et constaté plus d'une variante, ce qui explique les nombres supérieurs.

B. Caractéristiques du RITUEL

À l'analyse, la danse rituelle de l'aîné célibataire, dans ses avatars franco-ontariens, comporte au moins une dizaine de traits caractéristiques.

1. Cette prestation est d'abord obligatoire. Dans les fa- 
milles où on la pratique, aucun aîné célibataire ne peut en être dispensé. L'exemption accordée à un candidat à la prêtrise, par respect pour sa vocation, est singulière tout autant d'ailleurs que l'intransigeance remarquable qui ordonna une vindicte immédiate contre une aînée récalcitrante, qui fut pourchassée d'un bout à l'autre de la salle de danse pendant quelques minutes par un invité muni d'une vieille vadrouille sale. Ce sont des scrupules semblables qui condamnèrent l'aîné d'un couple de jumeaux à s'exécuter, qui n'accordèrent aucun traitement de faveur à un frère, pourtant déjà marié à son rang, mais reclassé célibataire par suite de son divorce, ni complaisance envers une mère concubine, jamais mariée officiellement, ni considération pour la soixantaine avancée de ces vieux oncles et tantes, encore célibataires. La contrainte est si impérieuse dans certaines familles qu'on n'hésitera pas à entraîner l'aîné vers l'accomplissement de son devoir, par la force physique le cas échéant. De telles actions s'avèrent toutefois extrêmes, car l'ambiance de la fête et l'alcool aident couramment à vaincre les résistances les plus solides des timides ou des endurcis.

2. Elle est ensuite théâtrale. Son scénario se développe selon une véritable mise en scène: au préalable, on a fait tricoter ou coudre les bas en secret et, suivant les circonstances, choisi la musique qui rythmera la danse; au cours du bal, un animateur annonce l'événement, exhibe à la vue de tous les bas excentriques et invite la victime à s'avancer, parfois à s'asseoir, à retirer ses chaussures pour que le cadet marié ou sa mère lui enfile les bas. Alors, l'aîné se lève, examine son allure, expose ses bas en paradant presque devant les invités qui s'en amusent et prennent des photos, puis, au signal de la musique, il se met à danser. S'il y a lieu, l'installation de l'auge, de la cuve ou d'un autre récipient qui en tient lieu, ajoute une dimension cocasse à la farce qui se prépare et à laquelle participent pleinement les familles et les amis. 
3. Elle est solitaire. Sans partenaire, le dérogateur est contraint de danser seul, sur la piste de danse ou dans l'auge, en exécutant des pas de gigue, tant que joue le rigodon ou la pièce qu'on a retenue pour lui; le tout dure de six à douze minutes. La présence de plusieurs aînés n'autorise aucunement à danser en couple ou en ronde, mais prolonge souvent le rituel. Il arrive que des parents interviennent, à tour de rôle, pour faire virevolter le danseur, l'étourdir, ou que quelques parents giguent autour de lui. On retiendra que cette danse en solitaire favorise l'exposition du célibataire disponible, constituant du même coup une forme de sollicitation.

4. Elle est rendue dérisoire, franchement bouffonne parfois, par le port de bas aux couleurs saugrenues et à l'allure invraisemblable, qui stigmatise le dérogateur. L'inconfort d'une cuve contenant de l'eau et de la glace, véritable traitement de choc pour stimuler le "patient", ou la difficulté de danser dans un espace aussi restreint qu'une auge symboliserait peut-être la situation impossible, voire déraisonnable et ridicule, dans laquelle cet aîné non encore marié s'est ainsi placé. La danse dans une auge à cochon, cet animal dont la saleté est proverbiale, ajouterait à la dérision et justifierait l'association «vieux garçon, vieux cochon", déjà répandue par le dicton populaire.

5. Elle est publique et exemplaire. Sujette aux plaisanteries des noceurs, la victime est le centre d'attraction du groupe qui fait cercle autour d'elle; le caractère public de sa dérogation est sanctionné par la divulgation de son état de célibataire. Son amende honorable sert de mise en garde et d'exemple pour les autres qui pourraient éventuellement se retrouver dans la même situation. Le fait que le cadet enfile les bas à son aîné, manifestant que ce dernier a été supplanté, ajouté, dans certains cas, au jet par les invités de sous qu'il devra, après sa prestation, ramasser un à un comme s'ils allaient favoriser sa réhabilitation, accentuent l'humiliation que le dérogateur doit subir. 
6. Elle est sympathique et divertissante aussi puisque les invités encouragent la victime, que certains l'accompagnent même un certain temps et qu'il s'agit bien d'un divertissement qui se déroule dans l'allégresse. On éprouve d'ailleurs une sympathie certaine envers un danseur qui se plie volontiers et gaiement à ce rite de passage, même si ce n'est plus pour la première fois.

7. Dans certains cas, elle est rentable. Les pièces de monnaie et les billets de banque qu'on lance au danseur sont recueillis à la main par un enfant ou balayés par un adulte; selon le nombre d'invités, la somme d'argent ainsi perçue peut varier de quelques dizaines à plusieurs centaines de dollars. Ce petit bénéfice n'appartient toutefois pas au danseur: il sera plutôt remis aux nouveaux mariés. Comme quoi la durée de la danse de même que l'encouragement et la participation des spectateurs ont un impact direct sur la somme offerte et qu'il résulte de cette sanction un appui tangible, lucratif, au bien-être des nouveaux époux.

8. Elle est mémorable. La danse de l'aîné sera fixée sur la pellicule photographique et généralement filmée avec l'ensemble des rituels du mariage. Elle ne fera pas partie pour autant de l'album officiel du couple qui réunit les grands moments du mariage, mais se limite généralement aux cérémonies et poses classiques: de la bénédiction paternelle, avant le départ de la maison, au découpage du gâteau de noce par les mariés. Car c'est là le travail du photographe professionnel que les mariés ont retenu; à moins que celui-ci n'appartienne au cercle de la famille ou des amis, son contrat aura pris fin avant le banquet. Aussi, la mémoire iconographique, fruit d'un travail d'amateur, sera-t-elle dispersée au sein des invités munis de caméras, photo et vidéo, et deviendra rapidement un bien périssable. On en retrouvera d'assez nombreux vestiges, au hasard des enquêtes, surtout dans les premières années qui suivent le mariage. Mais la mémoire vive des acteurs, ceux qui ont 
vécu l'événement, en gardera un souvenir, parfois plus durable que la mémoire morte des documents. L'aîné surtout ne l'oubliera jamais, car il en fut malgré lui la vedette et la victime, surtout si en plus il a conservé les bas, instruments de son "supplice».

9. Elle est vivante. La terminologie ondoyante qui désigne ce rituel, son déplacement de la maison vers une salle commerciale, l'adaptation de la musique aux modes contemporaines, l'ornementation de plus en plus spectaculaire des bas, souvent très colorés, voire recherchés, avec un débordement occasionnel sur d'autres pièces de vêtement, l'auge désormais nettoyée ou même remplacée par une cuve à lavage comptent parmi les éléments qui ont évolué à la faveur de conditions économiques plus propices; l'apparition récente du lancement de sous et d'argent, dont la somme se fait significative, le confirme. Mais le maintien de la sanction récréative de l'aîné célibataire dans le cadre du bal, le jour du mariage, de son déroulement varié, mais généralement sobre, de la danse exécutée selon un rythme traditionnel et de la fabrication domestique des chaussettes garantissent la permanence de la tradition ancienne.

10. Elle est enfin identitaire. C'est la perception générale que cette danse rituelle ne se pratique que dans la communauté française de l'Ontario. Les familles francoontariennes, qui ont de la parenté chez des anglophones ou des allophones, l'affirment: jamais ils n'ont assisté à un rituel similaire dans des noces autres que canadiennesfrançaises. Cette impression rejoint les nombreux témoignages négatifs que nous avons reçus de ces communautés anglo-ontariennes; les seuls Anglo-Ontariens qui avaient déjà vu ce rite de passage reconnaissaient que c'était dans des noces franco-ontariennes. À l'inverse, là où l'élément français domine dans les mariages mixtes, il s'est trouvé quelques familles, l'une d'origine italienne et l'autre d'origine irlandaise, pour adopter temporairement la tradition française. À ce facteur ethnique, on peut associer le fait 
suivant: dans le nord-est de l'Ontario, il ne s'est rencontré qu'environ deux douzaines de personnes de la communauté franco-ontarienne, soit $12 \%$ des témoins, qui n'ont jamais même entendu parler de cette tradition; le premier tiers de cette minorité est constitué d'immigrants d'Europe et d'Afrique où ce rituel est inconnu; le deuxième tiers se compose de Canadiens français du Québec et d'Acadie qui n'ont assisté à ce rituel ni dans leur province d'origine ni en Ontario; le dernier tiers, formé de Franco-Ontariens, comprend des individus provenant de familles qui ne pratiquent pas ce rituel ou des étudiants qui n'ont assisté encore à aucun mariage dans leur famille. Le caractère identitaire se profile donc davantage au sein de la majorité, qui compte $88 \%$ des témoins interrogés, qui connaît ou pratique cette coutume.

Les résultats de cette sanction sont au moins triples. Au rétablissement temporaire de l'ordre, perturbé par le comportement inconvenant du dérogateur et qui est la véritable finalité de cette cérémonie rituelle, s'ajoutent des bénéfices marginaux. Pour les gens de la noce, c'est là un divertissement coloré, qui plaît beaucoup et qu'ils apprécient parfois au point de le programmer même en l'absence de véritable dérogation. C'est, d'autre part, une publicité non recherchée pour la victime sanctionnée qui affiche sa disponibilité sur le marché du mariage; la communauté souhaite que la victime, à qui elle prodigue un si concret encouragement au mariage en la mettant ainsi au ban, puisse bientôt publier les bans de son mariage. Enfin, c'est, à l'endroit des nouveaux époux, une participation financière additionnelle et toujours la bienvenue, qui se substitue à d'autres rituels, comme le vol du soulier de la mariée, avec lequel on passe la quête parmi les invités, et la danse avec la mariée, sur le voile de laquelle on doit épingler des billets de banque ou verser autrement une somme convenue. Cette facette économique pourrait en outre favoriser la perpétuation de la danse de l'aîné célibataire. 


\section{III - Une tradition des Français d'Amérique}

A. “DANSER DANS L'AUGE» ET «DANSER SUR SES baS» AU QUÉbEC

\section{Danser sur ses bas}

Néanmoins, on s'en sera douté par la référence à Joseph Papineau, cette tradition est connue ailleurs qu'en Ontario. Nos informateurs franco-ontariens, qui ont souvent de la famille dans les régions limitrophes du Québec, en Abitibi, dans le Témiscamingue et en Outaouais notamment, ont régulièrement rapporté des observations de ce rituel dans la province voisine. À Hull, maintenant Gatineau, et dans les environs, "danser sur ses bas» est pratique courante. Un témoin nous écrit:

Je suis résidente de l'Outaouais québécois et d'aussi loin que je me souvienne, les aîné(e)s dansent sur leurs bas (très colorés avec grelots ou autres) lors des mariages. Même, dans les derniers mariages où je suis allée, les gens autour de la piste de danse lancent des pièces de monnaie aux danseurs. Les danseurs sont sur le plancher de danse et non dans une auge ou autre. Mais je dois aussi ajouter que mon conjoint qui vient de Québec, ne connaissait pas cette coutume ${ }^{65}$.

Dans le Témiscamingue québécois, à Ville-Marie, on danse sur des bas de laine tricotés et décorés, et l'argent lancé est recueilli par les garçons d'honneur; à NotreDame-du-Nord et à Nédelec, un autre informateur a assisté huit fois à ce rituel entre 1973 et 1999: l'aîné dansait sur des bas ordinaires et on ne lançait pas d'argent, comme d'ailleurs à Earlton et à New-Liskeard, du côté ontarien tout près, ou à Ottawa et à Sturgeon-Falls. À Val-d'Or, en Abitibi, on parle de «danser en pieds de bas» surtout, mais aussi de "danser sur ses bas». Une informatrice, qui a «dansé en pieds de bas au mariage de [s]on frère en 1987, à Hearst, Ontario", décrit les bas:

Habituellement, ils sont confectionnés par un membre de la famille pour l'occasion, mais ils sont parfois achetés. Mais ce sont toujours des bas de laine. J'ai toujours vu des bas unis, mais

${ }^{65} \mathrm{M}^{\mathrm{me}}$ Andrée Groulx, Université d'Ottawa, note du 11 juin 2001. 
parfois dépareillés. Après la danse, dans mon cas, les bas ont été remis à la personne qui les avait achetés ${ }^{66}$.

Ce sont "les mariés [qui] ont enfilé les bas" aux deux aînées sanctionnées: chacune portait une chaussette rouge et une autre brune; on ne lançait pas d'argent. Dans une autre famille de Val-d'Or, entre 1980 et 2000 , la danse s'exécute en bas jaunes tricotés par la mère de la mariée; on ne lance pas d'argent non plus et elle s'est déroulée de la même manière à Fauquier, Ontario, en 1989. À RouynNoranda, comme à Hearst, c'est la «danse en pieds de bas», dans des chaussettes tricotées par une femme de la famille avec des restants de laine, aux couleurs vives, qu'on garnit de glands, d'attaches ou d'appliqués. Le témoin, qui l'a observée en 1965 et 2000 , note qu'on y lançait, en plus de l'argent, des confettis et du riz, et qu'on l'avait pratiquée aussi à Thetford-les-Mines. À Val-d'Or, à Rouyn et à O'Baska, on "danse en pieds de bas", dans des bas ordinaires, confie un informateur qui a été témoin de ce rituel entre 1959 et 1998 . Un autre observateur, qui l'a vu vingt fois depuis les années 1970, confirme ce fait pour Rouyn et Montréal, au Québec, et pour des localités ontariennes, Hearst, Verner, Lavigne, Sturgeon-Falls, New-Liskeard et Ottawa: on danse sur des bas ordinaires ou des bas spéciaux et parfois on lance de l'argent. À Saint-Laurent-deGallichan (Abitibi), on danse aussi sur ses bas, mais ce sont des "bas spéciaux", tricotés à la main et décorés de grelots. Le même témoin, né en 1938 et résidant maintenant à Sudbury, y a encore vu quelqu'un danser en raquettes à neige; sauf une fois en 1995, où on a lancé de la menue monnaie destinée au danseur, on ne jette habituellement pas d'argent. À Senneterre, un informateur, qui mentionne que ce rituel serait aujourd'hui en déclin dans sa famille, l'a vu trois ou quatre fois entre 1960 et 1970: réservé aux hommes, jamais aux femmes, il ne se limitait toutefois pas ${ }^{66}$ Témoignage de $\mathrm{M}^{\mathrm{me}} \mathrm{Jeanne}$ d'Arc Lanouette, 60 ans, née en 1940 à NotreDame-du-Nord, Témiscamingue, et domiciliée à Val-d'Or, Abitibi-Est, le 18 juillet 2000 . 
à l'aîné, car tous les célibataires non mariés devaient danser sur leurs bas, ce qui était une façon de les identifier; ils dansaient dans les chaussettes ordinaires qu'ils portaient pour le mariage et on ne leur lançait pas d'argent.

Dans la périphérie de Montréal, zone qui a fourni une bonne part de la population franco-ontarienne, principalement dans ses régions nord et ouest, on trouve encore quelques signes de la présence de la tradition de la «danse sur les bas", mais sa popularité serait en nette régression. À Saint-Joseph-du-Lac (Deux-Montagnes), «danser sur ses bas» se fait sur des bas ordinaires; le témoin, qui l'a aussi observé à Rivière-des-Prairies (Hochelaga, 1980), à l'Isleaux-Coudres (1989) et à Saint-Rémi-d'Amherst (Papineau, 1996), l'a en outre vu en Outaouais et à Hawkesbury. Un témoin de Sudbury, mais originaire de Montréal, se rappelle l'avoir vu une fois à Shawinigan en 1975: l'aîné "dansait sur ses bas" tricotés de laine multicolore et garnis de grelots, sans lancement d'argent. Cette dernière localisation est aussi confirmée par le fichier du Trésor de la langue française au Québec qui a relevé cette phrase d'un informateur de Shawinigan-Sud en 1980: "La fille du rang gauche dansait en bas jaunes à [la] veillée des Fleur[y $]^{67} »$; il s'agit bien entendu d'une vieille fille qui exécute la sanction prévue en portant des bas qui rappellent ceux de l'Ontario. Un témoin de Québec a vu cette danse en Montérégie dans les années 1980: une fille de Mascouche (L'Assomption) épousait un garçon de Montréal; la victime était l'aînée et dansait en bas ordinaires. À Laval, un témoin se rappelle avoir entendu l'expression «la danse du chausson", sans plus, car il n'a jamais assisté à un tel rituel. Par contre, une informatrice de la ville des Laurentides (L'Assomption), dans la banlieue nord de Laval, se souvient très bien de la "danse sur ses bas", à laquelle elle a assisté en 1981 et 1986:

\footnotetext{
${ }^{67}$ Trésor de la langue française au Québec [TLFQ], enquête d'un chercheur anonyme auprès d'un témoin de 65 ans, 1980.
} 
Je suis du Québec et nous c'est seulement «sur les bas», mais la personne qui a pensé d'avance à faire danser l'autre «sur ses bas" a choisi au préalable des bas soit très laids, soit très rigolos [. .]: des bas de couleur différente dans chacun des pieds ${ }^{68}[$. .], des gros bas de laine gris avec une ligne rouge [. .], des bas multicolores ${ }^{69}$.

On ne lance pas d'argent. Le même rituel a été signalé à Saint-Lin (L'Assomption), au nord de Montréal. Une informatrice de Sainte-Adèle (Terrebonne) a vu cette tradition une seule fois, vers 1952. Il s'agissait d'une danse en solitaire, sur une musique rythmée, le temps d'une chanson, que l'aîné a exécutée sur ses bas, après avoir retiré ses souliers, après le repas de noces. "Ce n'était pas une pratique courante dans ma famille." Elle se souvient qu'on avait prévenu l'aînée par ces mots: "Tu vas danser sur tes chaussons!» La danseuse portait des bas ordinaires et on ne lançait pas d'argent ${ }^{70}$. On trouve aussi l'expression "danser sur ses chaussons» en annexe à un récit inspiré de la vie d'une octogénaire qui aurait habité dans la région de Montréal entre 1870 et 1959 . Lorenzo Proteau écrit: «Si dans une famille, une fille se mariait avant son aînée devenue vieille fille, on disait de la jeune mariée "qu'elle avait fait danser sa sour sur ses chaussons", ce que, littéralement, la pauvre sœur vieille fille était obligée de faire le 25 novembre suivant ${ }^{71} »$. Une collègue nous a encore signalé l'existence de la «danse du chausson» dans la région de Saint-Hyacinthe ${ }^{72}$. De même, on "dansait sur ses bas" à Mont-Laurier (Labelle):

\footnotetext{
${ }^{68}$ La photo transmise montre un danseur chaussé d'un bas rouge et d'un bas vert, février 1986.

${ }^{69} \mathrm{M}^{\text {me }}$ Danielle Couture-Haché, 41 ans, née à Montréal en 1958, demeurant à Dieppe, Nouveau-Brunswick, 1999.

${ }^{70} \mathrm{M}^{\text {me }}$ Françoise Poulin-Balthazard, 67 ans, née en 1932, le 4 juillet 1999.

${ }^{71}$ Lorenzo Proteau, Grand-mère 'Toinette m'a raconté, [Montréal], Les Éditions Priorités, [1981], p. 188.

${ }^{72}$ Dans une note datée du 20 avril 1999, Christiane Noël ${ }^{\dagger}$ nous écrivait: "Dans le cadre de la série télévisée "On aura tout vu", j'y ai vu [automne 1998] "La danse du chausson" très bien expliquée [région de Saint-Hyacinthe, je crois]. Cette série est produite en collaboration avec la Société Radio-Canada
} 
En 1990, j'ai assisté à des noces à Mont-Laurier et la demoiselle que j'escortais était l'aînée de la mariée. Sa grande peur était justement d'avoir à «danser sur ses bas». Pour une raison que j'ignore, la "danse" n'a pas eu lieu. C'est vrai que la demoiselle n'était que sœur adoptive de la mariée; cette famille provenait de Ferme-Neuve [Labelle] ${ }^{73}$.

D'après la conjointe de cet informateur, le rituel existerait aussi «dans la Haute-Mauricie». À Saint-Ambroisede-Kildare (Joliette), cette tradition serait aussi connue ${ }^{74}$. Mais, à Montréal même, les attestations sont rares. Interrogeant la chanteuse Julie Masse sur les circonstances de son mariage, célébré à Longueuil en juillet 1993, le journaliste montra qu'il connaissait bien cette tradition:

[Q] Est-ce que ta sœur Hélène a dansé sur ses bas?

[R] (Amusée par la question:) Non! Pourquoi?

[Q] Parce que, lorsque la cadette de la famille se marie et que l'aînée est encore célibataire, cette dernière, selon la tradition, doit enlever ses souliers et danser sur ses bas.

[R] Ah bon! Je ne savais pas ça! Avoir su! Il faut dire qu'il y a tellement de traditions. Disons qu'Hélène y a échappé! (rires) ${ }^{75}$.

\section{Danser dans l'auge}

Au Québec, la tradition de la «danse dans l'auge» serait restreinte aux régions du Centre et de l'Ouest. La première mention de cette expression a justement été trouvée en 1971 dans le comté de Pontiac, à l'île-du-Grand-Calumet, par un enquêteur de l'Atlas linguistique de l'est du Canada: "On dit d'une cadette qui se marie avant son aînée: "Elle l'a fait danser (l'aînée) dans l'auge à cochon"76"»; mais cet

(français) et une équipe de production où apparaît le nom de Robert Tremblay, créateur de la série. Cette série est utilisée comme "remplissage" à la grillehoraire. Durée: 12 minutes. Diffusion sporadique-irrégulière à R[adio]-Canada, Télé-Québec et Canal D.» Cette piste a été explorée en vain.

${ }^{73}$ M. Ronald Palardy, Hull, le 8 et le 15 juin 2001.

${ }^{74}$ Renseignement fourni par M. Lucien Ouellet, le $\mathbf{1}^{\text {er }}$ novembre 1999.

${ }^{75}$ André Carrière, «Ma nouvelle vie de femme mariée», dans 7 Jours, [Montréal], vol. 4, n 46, 25 septembre 1993, p. [2] du document consulté sur la toile électronique.

${ }^{76}$ Gaston Dulong et Gaston Bergeron, Le Parler populaire du Québec et de ses 
ouvrage consacré à la langue populaire n'explique pas le rituel. En Mauricie, des enquêteurs du groupe de Gérard Bouchard ont consigné quelques attestations occasionnelles de cette expression ou du rituel ${ }^{77}$ : un témoin de Trois-Rivières, né en 1905, avait déjà entendu parler de l'auge, mais sans plus ${ }^{78}$; un autre, de Saint-Sévère (SaintMaurice), né en 1901 et marié en 1924, se rappelle, à propos de l'expression «danser dans l'auge», qu'il y avait "trois petits auges" à ses noces, parce qu'il avait trois frères aînés non mariés, mais il n'en dit pas davantage ${ }^{79}$; enfin, un informateur de Saint-Tite (Champlain), né en 1902 et marié en 1929, connaissait l'expression «danser dans l'auge", mais non le rituel qu'on ne pratiquait pas dans sa famille ${ }^{80}$. Pour sa part, le fichier du TLFQ compte deux références à l'expression: à Saint-Georges ou Grand'Mère (Laviolette), on a noté en 1981 la phrase "Jacques a fait danser sa sœur à l'auge» pour signifier «se marier avant sa sœur ou son frère aîné ${ }^{81_{1}}$; à Shawinigan, en 1980, dans le même esprit, "[l]es gens disaient: je vais te faire danser dans l'auge ${ }^{82} »$; mais, là encore, on ne décrit pas le rituel. De même, dans le comté de Mégantic, à Bernierville, un témoin né en 1907 avait déjà entendu l'expression «danse dans l'auge», mais n'avait jamais vu le rituel ${ }^{83}$.

Cependant, dans un ouvrage récent, Le Mariage dans la vallée du Haut-Richelieu au XX $X^{e}$ siècle, Martine Tremblay

\footnotetext{
régions voisines. Atlas linguistique de l'Est du Canada [ALEC], Québec, Office de la langue française, «Études et dossiers», 1980, v. 7, pp. 2864-2865: enquête 62. ${ }^{77}$ Il s'agit des données contenues dans le fichier RIMA, dépouillement des entrevues conduites dans le cadre d'un projet de recherches sur les dynamiques culturelles interrégionales dirigé par Gérard Bouchard et son équipe de l'Université du Québec à Chicoutimi.

${ }^{78}$ RIMA 1993.

${ }^{79}$ RIMA 1989.

${ }^{80}$ RIMA 1993.

${ }^{81}$ TLFQ enquête de Pierre Dessureault auprès d'un témoin de 61 ans, 1981.

${ }^{82}$ TLFQ enquête de Josée Dessureault, juin 1980.

${ }^{83}$ RIMA 1992.
} 
montre qu'une forme de cette danse est toujours populaire:

Une autre coutume évoque cette fois non pas le prochain mariage, mais le mariage raté, lorsqu'un cadet se mariait avant son ou ses aînés. Les invités forçaient alors ces derniers à «danser dans l'auge» : rite dérisoire à l'endroit du célibataire, il visait peut-être aussi à stimuler la recherche d'un conjoint dans le cercle des apparentés puisqu'il l'amenait à danser seul face aux invités, dans une mangeoire d'animaux ou un contenant qui la [le?] représentait. Peu d'informateurs mariés dans la période 1920-1940 ont vu un frère ou une sœur «danser dans l'auge» à leur propre mariage; par contre, presque tous connaissaient la coutume (note 36: Deux témoins ont vu le rite à leur propre mariage, 18 le connaissaient sur les 22 informateurs à qui la question a été posée. [22/35]).

[. .] Les noces récentes mettaient en scène une panoplie de jeux qui divertissaient les invités tout en ayant une signification qui dépassait l'amusement. La «danse dans l'auge», «dans l'eau» ou "dans la bassine» est encore largement connue parmi les jeunes couples même si l'imprécision de l'appellation dénote la méconnaissance de l'origine du rite (note 38: Cinq couples l'ont vu à leur[s] noces, 16 autres connaissaient le rite sur 29 informateurs à qui la question a été posée. [29/30]). La professionnalisation de l'animation des noces a certainement contribué à la diffusion du rite. Un couple n'avait jamais entendu parler de cette coutume avant leur mariage; l'animateur a suggéré ce jeu, qui n'a finalement pas eu lieu (note 39: E58) ${ }^{84}$.

Trois de nos informateurs confirment la présence de ce rituel dans cette région. Le premier, qui fut commerçant à Napierville de 1929 à 1999, a entendu parler de la «danse dans l'auge" qui se serait passée à Saint-Jean-sur-Richelieu il y a longtemps ${ }^{85}$. Selon une informatrice, quand un garçon ou une fille plus jeune se mariait avant son aîné, celui-ci «dansait dans l'auge", avec ses souliers, le soir des noces. Lauge était une boîte de bois ou de carton. Cette tradition n'était pas fréquente dans son milieu. Au mariage de $M^{\text {me }}$

${ }^{84}$ Martine Tremblay, Le Mariage dans la vallée du Haut-Richelieu au XXe siècle. Ritualité et distinclion sociale, Sainte-Foy, PUL, "Géographie historique», 2001, pp. 186-187.

${ }^{85}$ Renseignement de M. Aimé Provost, 95 ans (né en janvier 1906), communiqué le 18 mai 2001 et obtenu par l'intervention de $\mathrm{M}^{\text {me }}$ Guylaine Poissant. 
Thomas Poissant, vers 1930 (il y a 70 ans), à Napierville, il y avait deux frères aînés: l'un a dansé, mais l'autre n'a pas voulu. La noce se faisait à la maison. Cette coutume, qui serait aujourd'hui disparue dans sa famille, visait à se moquer du célibataire ${ }^{86}$. Nous avons aussi rencontré la métaphore "danser dans l'auge», que connaissait bien le dernier témoin, originaire de Saint-Cyprien de Napierville, mais sans le rituel ${ }^{87}$.

Plus à l'ouest, dans le Témiscamingue québécois, une informatrice relate son expérience personnelle:

J'ai dansé dans l'auge, en 1965, au mariage de ma sœur à Fabre, au Témiscamingue. L'auge avait été apportée par des cousins de Rémigny. [Ceux-ci] l'ont placée au milieu de la place et nous avons dansé seules dedans (nous étions deux), mais là encore sur de la musique de set carrés8.

Ailleurs au Québec, on n'a guère recensé cette forme particulière du rituel, si ce n'est dans la Beauce selon I'ethnologue Jean-Claude Dupont ${ }^{89}$.

\section{Danser dans une cuve}

Quant à la variante "danser dans une cuve», elle serait connue dans la région du Richelieu, si l'on interprète correctement l'allusion de Martine Tremblay aux dénominations «danse dans l'eau" ou "dans la bassine» dans la citation rapportée. Des informateurs franco-ontariens ont assisté à des noces dans les comtés de Gatineau, d'Argenteuil et de ${ }^{86}$ Renseignement de $M^{\text {me }}$ Rachel Boire-Guay, 92 ans (née en 1908 , elle est la
cadette de 13 enfants), communiqué le 14 mai 2001 et obtenu par l'interven-
tion de $M^{\text {me }}$ Guylaine Poissant.
${ }^{87}$ Renseignement de $M$. Roland Pinsonneault, 86 ans, de Gravelbourg
(Saskatchewan), obtenu à Régina le 18 septembre 1999 ; né à Saint-Cyprien de
Napierville (Québec) le 22 septembre 1914 , il est arrivé à Gravelbourg en
1919 , à l'âge de 4 ans.
${ }^{88}$ Témoignage de $M^{\text {me }}$ Jeanne d'Arc Lanouette, 60 ans, née en 1940 à Notre-
Dame-du-Nord, Témiscamingue, et domiciliée à Val-d'Or, Abitibi-Est, le 18
juillet 2000 .
${ }^{89}$ À deux occasions, le 28 septembre 1999 et le 27 mai 2001 , J-C. Dupont a
confirmé ce fait en se rappelant qu'une étudiante avait retracé la “danse dans
l'auge» à Beauceville vers 1975 . 
Pontiac, entre les années 1950 et 1992, où la présence de la "cuve» est dûment attestée. Cette tradition aurait existé à Maniwaki (Gatineau); à Calumet (Argenteuil), vers 1975, un témoin franco-ontarien né à Hawkesbury a dansé sur ses bas et dans une cuve contenant de l'eau: comme deux célibataires ont dû se prêter à ce rituel, chacun a dansé à tour de rôle puis en même temps; le manège dura une bonne heure et s'acheva quand les aînés s'assirent dans l'eau. Un autre témoin, né à Gatineau en 1934, se rappelle avoir vu à quatre ou cinq occasions un aîné dans une cuve remplie de glace, vers 1950; il portait de gros bas de laine gris avec une ligne rouge et dansait pendant qu'on jouait un morceau au violon et que tout le monde chantait; ce rituel, qu'il n'a vu qu'au Québec, était moins fréquent que la danse sur les bas. Plus récemment, vers 1992, un témoin de la région de Sudbury vit, au cours d'une noce à Fort-Coulonge (Pontiac), l'aîné danser nu-pieds dans une cuve métallique, qui sert au lavage; comme on y déposait des fruits et des légumes avariés, les invités franco-ontariens, surpris de la chose, y jetèrent des "cennes", selon leur usage ${ }^{90}$.

\section{B. “LA DANSE DANS L'AUGE " EN ACADIE}

Dans sa synthèse des traditions populaires acadiennes, l'ethnologue québécois Jean-Claude Dupont a livré ce qui semble la première description connue de la "danse dans l'auge», une sanction rituelle que l'aîné doit exécuter le "soir de la cocarde" au Nouveau-Brunswick.

Le soir de la cocarde, la veille des noces, le futur mari venait chez sa fiancée coiffé d'un haut de forme garni de trois rubans de couleur bleu, blanc et rouge. Il était suivi de ses amis et il ouvrait la danse. C'est souvent ce soir-là que l'on punissait le vieux garçon et la vieille fille de la famille où avait lieu le mariage. $\grave{A}$ Cocagne, à Richibouctou, à Moncton, à Memramcook et à Shédiac, un musicien jouait un air et la vieille fille devait danser dans l'auge à cochon, entré[e] dans la maison pour la circons-

${ }^{90}$ Renseignement communiqué par M. Léo Larivière, Hanmer, le 13 juin 2002. 
tance. Quand c'était un vieux garçon qu'on voulait punir de ne pas s'être marié, il devait manger des galettes ou du cuisinage dans la même auge.

Ces dernières années, la vieille fille doit plutôt danser autour de l'auge, et [,] lorsqu'elle s'est exécutée [,] on lui remet une bouteille de vin. Une informatrice de vingt-trois ans en 1973, Jeanne Dupuis, de Memramcook, a dansé la cocarde, le 12 mai 1973 parce que sa sœur plus jeune qu'elle prenait époux ${ }^{91}$.

Une informatrice de Jean-Claude Dupont, interrogée en 1966, avait aussi précisé l'époque où elle avait assisté à cette tradition: "En 1955, à Memramcook, la fille danse dans l'auge et le garçon mange dans l'auge ${ }^{92} »$. Dans son roman Pélagie-la-Charrette, Antonine Maillet fait brièvement allusion à cette coutume, qu'elle situe deux siècles plus tôt en 1776, quand Pélagie s'étonne que sa fille Madeleine fût demandée en mariage: "Vingt ans, tu vois bien?, pense-t-elle. À cet âge-là, Pélagie, tu avais déjà mis tous tes enfants au monde, souviens-toi. Une fille qui passe vingt ans sans offrir sa main pourrait manger dans l'auge, comme c'est croyance et coutume au pays ${ }^{93} . »$ Récemment, en réponse à notre enquête, Ronald Labelle, du Centre d'études acadiennes (CÉA) de l'Université de Moncton, a pu confirmer la tendance contemporaine à "danser autour de l'auge" et noter que l'auge contient maintenant de l'alcool, "mélange de bière et de fort", que le célibataire doit boire. Alors qu'il n'avait pu repérer au CÉA aucune donnée relative à cette tradition, voilà qu'un sondage auprès d'un groupe d'étudiants lui procura rapidement une première série de variantes:

\footnotetext{
${ }^{91}$ Jean-Claude Dupont, Héritage d'Acadie, Montréal, Leméac, "Connaissance", 1977, pp. 231-232.

${ }^{92}$ Sœur Lucille Bourgeois, coll. J.-C. Dupont, ms. 5102, juillet 1966.

${ }^{93}$ Antonine Maillet, Pélagie-la-Charrette. Roman, [Montréal], Leméac, 1979, p. 236. D'avance, cet auteur avait expliqué l'expression dans un ouvrage précédent: «Faire manger dans l'auge - supplanter (s'applique surtout à l'amour)" (Antonine Maillet et Rita Scalabrini, L'Acadie pour quasiment rien. Guide historique, touristique et humoristique d'Acadie, [Montréal], Leméac, [1973], p. 119).
} 
Les étudiants du nord du N[ouveau]-B[runswick] ne connaissent pas la coutume, mais certains qui viennent de la région de Moncton sont allés à des noces où on a accompli un rituel avec l'auge à cochon. J'ai trois variantes à rapporter: un étudiant a vu une fille aînée danser autour de l'auge, au son du violon; une autre a vu l'aînée danser autour de l'auge et aussi boire de la bière dans l'auge à l'aide d'une longue paille; enfin, la semaine dernière avait lieu la noce de la fille d'une secrétaire ici, où le frère aîné célibataire a dû se mettre à quatre pattes et boire dans l'auge. Ses amis avaient au préalable versé un mélange de bière et de fort dans l'auge. On voit donc qu'ici la tradition de danser dans l'auge se transforme. De plus en plus, on fait boire de l'alcool dans l'auge, en plus de faire danser la personne autour de l'auge ou encore au lieu de la faire danser. Aussi, contrairement à ce qui se faisait anciennement, c'est lors de la noce que ça se passe et non le soir de la cocarde. La cocarde n'existe plus depuis longtemps comme fête ${ }^{94}$.

Cette pratique est toujours très vivante dans la région de Richibouctou (Kent): pour l'occasion, on fabrique une auge de bois dans laquelle l'aîné doit danser, un pied dedans, un pied dehors, sur la musique d'un rigodon. Rares sont les noces dans la famille d'une informatrice où on ne programme pas la "danse dans l'auge ${ }^{95} "$. Un autre témoin, qui avait appris l'existence de cette tradition de ses scurs aînées et qui a, par la suite, vu «danser dans l'auge» quatre fois entre 1969 et ce jour d'octobre 1999 où son propre fils avait dû s'y soumettre à son tour, apporte un témoignage plus détaillé:

Aujourd'hui, on fait danser la personne autour de l'auge. On place l'auge à terre dans la salle et on y verse de la boisson. Le danseur s'avance, danse autour de l'auge au son d'une musique rapide et, à la fin, il se met à quatre pattes et boit dans l'auge. Lors du mariage de la fille de Léa Girouard, son fils a dû danser dans l'auge. Ne connaissant pas la coutume, il s'est avancé et

\footnotetext{
${ }^{94}$ Ronald Labelle, Moncton, Nouveau-Brunswick, Centre d'études acadiennes, note télécopiée du 28 octobre 1999,1 p. ms.

${ }^{95}$ Communication de $\mathrm{M}^{\text {me }}$ Roberta Richard, Richibouctou, Nouveau-Brunswick, le 3 juillet 2001, dont l'époux a dansé dans l'auge vers 1960-1965; son fils, Robert Richard, a d'ailleurs enregistré son père à ce sujet.
} 
s'est mis à genoux tout de suite pour boire dans l'auge le mélange de boisson que ses amis y avaient versé. À Grande-Digue, on garde une auge qui sert à chaque fois que la coutume est pratiquée à la salle communautaire. C'est une auge propre, faite spécialement pour la coutume ${ }^{96}$.

Organisé par les amis de la victime, le rituel survient en dernier lieu, pendant la danse et après l'achèvement des autres cérémonies. C'est au moment où l'aîné s'y attend le moins, ajoute le témoin, qu'ils installent l'auge au milieu de la salle, annoncent l'événement, et font avancer l'aîné célibataire. Pendant la danse, qui ne dure que quelques minutes, les amis se regroupent autour pour l'encourager, mais aussi pour se moquer de lui. La danse doit être vive sans pour autant être toujours une gigue, car cela dépend des musiciens ${ }^{97}$. Un dernier informateur corrobore ce scénario pour la région de Cocagne (Kent) et explique comment la boisson est versée dans le récipient:

en milieu de soirée, on arrête la fête pour souligner qu'un aîné, frère ou sœur, n'est pas marié. On place une petite mangeoire en bois, faite en "V», au milieu de la salle et le condamné doit danser autour de l'auge tandis que les gens remplissent cette auge à même leurs verres. Le condamné doit danser et boire dans l'auge un certain temps avant que la soirée puisse continuer. [..] Un autre collègue, de la région d'Edmunston [Madawaska], dit que, par chez lui, on danse littéralement dans l'auge, qui est en réalité une boîte de carton géante, dans laquelle on a placé du grain ${ }^{98}$.

La modernisation aurait procuré quelque adoucissement à la tradition d'origine pour autant que l'on puisse en juger d'après le témoignage de trois Acadiens de la NouvelleÉcosse, qui ont participé à de telles célébrations dans la première moitié du $\mathrm{XX}^{\mathrm{e}}$ siècle. À Concession, village du comté de Digby, on réservait la "danse dans l'auge à cochon»

${ }^{96}$ Témoignage de $\mathrm{M}^{\text {me }}$ Léa Girouard, qui a assisté à ce rituel à Grande-Digue, à Shédiac-Bridge et à Bouctouche, Nouveau-Brunswick, consigné par Ronald Labelle, le 16 décembre 1999, d'après notre questionnaire.

${ }^{97}$ Loc. cit.

${ }^{98}$ Témoignage de M. Ricky Richard, né en 1970, obtenu le 17 juillet 2002. 
aux garçons seulement. Pendant la Deuxième Guerre mondiale, en 1945, ce rituel s'est déroulé à l'extérieur de la maison, le soir de la noce, sur l'estrade très peu éclairée qu'on avait montée exprès pour la danse; en cas de mauvais temps, la danse avait lieu dans la maison ou dans la grange. L'auge à cochon avait été nettoyée, parce que, précise le témoin, "ç'aurait coulé». L'aîné dansait en pieds de bas dans l'auge à la musique d'un joueur de violon; s'il y avait plusieurs danseurs, ils dansaient à tour de rôle. La danse n'était "point longue», parce que c'était très inconfortable, le fond de l'auge, qui mesurait environ un mètre sur trente centimètres (quatre pieds sur un), ayant la forme d'un triangle inversé $e^{99}$. Une autre informatrice, de La Butte, raconte que son oncle, l'aîné de la famille, avait dû «danser dans l'auge" au mariage de son père (frère cadet de l'aîné, né en 1891 et marié à l'âge de 30 ans) en 1921 . Au mariage du témoin, en 1945, son oncle, qui tenait un magasin dans le voisinage, a dit à sa sœur aînée: "Faut que tu ailles danser dans l'auge!» Elle a vraiment dansé dans l'auge, sur le plancher du magasin. C'était la dernière fois, et peut-être la seule, qu'elle a vu cette tradition aujourd'hui disparue ${ }^{100}$. Un dernier témoin a assisté une seule fois à ce rituel. C'était le jour du mariage d'une cousine, à Pointe-de-l'Église, vers 1925, durant la soirée de noce: sa sœur aînée avait dansé dans l'auge. Il ne se rappelle pas si elle était chaussée ou nu-bas ${ }^{101}$. La tradition néo-écossaise de la région de Digby s'appliquait donc tantôt aux garçons exclusivement, tantôt aux aînés célibataires, garçons et filles; à Chéticamp (Inverness), dans l'îledu-Cap-Breton, la tradition n'a pas été attestée ${ }^{102}$.

\footnotetext{
$\overline{{ }^{9}}$ Témoignage de $\mathrm{M}^{\mathrm{me}}$ Jacqueline Thibault, 78 ans (née en 1923), de Comeauville (Digby), Nouvelle-Écosse, obtenu le I 4 mai 2001.

${ }^{100}$ Témoignage de $\mathrm{M}^{\mathrm{me}}$ Angèle Boudreau, 78 ans (née en 1923), de La Butte (Digby), Nouvelle-Écosse, obtenu le 7 mai 2001.

${ }^{101}$ Questionnaire de M. Félix Thibodeau, né à Pointe-de-l'Église en 1907, de Paradise (Annapolis), Nouvelle-Écosse, rempli le 31 mai 2001.

${ }^{102}$ Barbara Le Blanc, qui a interrogé 57 témoins sur la danse et ses interdictions dans trois paroisses de cette région, n'a pas rencontré cette tradition; voir
} 
Aux États-Unis, chez des populations qui ont subi une influence acadienne, la danse dans l'auge est connue. À la frontière du Nouveau-Brunswick et du Québec, dans l'État du Maine, Roger Paradis, qui a mené là plusieurs missions folkloriques, connaît bien ce rituel:

«Danser dans l'auge à cochon" était vraiment une coutume au Madawaska des ancêtres. Ordinairement, l'auge était lavée et brossée en préparation de la noce. À quelques occasions, une paire de bas multicolores et tricotés furent utilisés; en d'autres occasions, on présentait à l'aîné célibataire (garçon ou fille) une paire de bottes très grandes qui paraissaient remarquablement usées en comparaison de ses habits du dimanche. Si l'aîné était musicien, on pouvait l'inviter à danser en s'accompagnant de sa propre musique. C'était une plaisanterie, quoique probablement mal prise secrètement - peut-être même redoutée — par l'aîné ainsi marginalisé ${ }^{103}$.

Cet informateur a été témoin de la tradition à trois occasions dans des localités différentes du Maine: à Frenchville, vers 1956, à Madawaska, en 1960, et à Saint-John, en 1964. Il explique ce phénomène par «un besoin et un désir d'encourager le mariage et la propagation, surtout en Amérique du Nord où le territoire était vaste et la population petite.» Tout à fait au sud des États-Unis, en Louisiane, l'expression persistait encore chez les descendants des Acadiens, au temps des recherches de Corinne Saucier, mais sans le rituel toutefois: "Si les enfants de la famille ne se marient pas dans l'ordre chronologique, on dit que le plus jeune a fait danser son frère dans l'auge. Quand une jeune fille perd son prétendant, que sa rivale lui a coupé l'herbe ${ }^{104}$."

"To dance or not to dance: the Church and group social control in Ch[é]ticamp, Cape Breton Island, Nova Scotia", Thèse de maîtrise ès arts, Université Laval, mars 1986, 272 pages. D'autre part, le père Anselme Chiasson nous écrit dans sa lettre du 24 juin 1999: «Personnellement, je ne pense pas avoir entendu parler de cette tradition et ne l'ai jamais recueillie. Je crois pouvoir dire avec certitude qu'elle n'a jamais existé à Chéticamp.»

${ }^{103}$ Roger Paradis, lettre du 7 juillet 1999.

${ }^{104}$ Corinne L. Saucier, Traditions de la paroisse des Avoyelles en Louisiane, Philadelphie, American Folklore Society, "Memoirs of the American Folklore Society» 47, 1956, p. 61 . 
Pour sa part, Dennis Au rapporte deux témoignages qu'il a dénichés chez les "mangeurs de rats musqués ${ }^{105}$ " de l'État du Michigan. Celui de James Reaume, qui n'a jamais lui-même vu le rituel, assure d'abord la présence, du côté étatsunien de la rivière du Détroit, de la «danse dans l'auge" qu'on réservait à l'aînée si sa cadette convolait avant elle ${ }^{106}$. Mais une recherche plus poussée et toute récente devait l'amener à joindre John Reaume. Ce résidant de Monroe, né à Newport, Michigan, en 1955, a été témoin à deux occasions d'une cérémonie qu'on appelait la "danse de l'auge à cochon ${ }^{107}$ ». Il se rappelle surtout de son déroulement au mariage de son cousin, Dennis Reaume, il y a une quinzaine d'années, vers 1985-1987, quand l'aîné, David, dut s'y soumettre:

Le rituel eut lieu vers le milieu de la réception des noces. L'auge employée, qu'on se transmettait dans la famille Lefebvre, avait été spécialement fabriquée pour cet usage. C'était une auge de bois mesurant environ quatre pieds de longueur sur un pied de largeur. La danse fut exécutée au son de la musique de l'orchestre engagé pour l'occasion, un groupe du voisinage, formé pour l'essentiel de membres de la famille Robert, et qui comptait, parmi ses instruments, un violon et un accordéon. Le témoin John Reaume n'a pas souvenir qu'on ait joué quelque musique ou chanson particulière, mais c'était une musique rapide. L'aîné, David Reaume, dansa autour et par-dessus l'auge. Sa danse, qui dura environ cinq minutes, était une combinaison de pas tantôt glissés, tantôt gigués. Au dire du témoin, son cousin David exécuta sa danse avec une telle fougue qu'il sidéra les spectateurs qui s'en montrèrent très satisfaits ${ }^{108}$.

${ }^{105}$ Expression tirée de la communication de Dennis $\mathrm{Au}$, «The Muskrat French: The Survival of French Canadian Folklife on the American Side of Le Détroit ", présentée au colloque «Le Passage du Détroit. Trois cents ans de présence française», Université de Windsor, le 20 juillet 2001, 17 p. ms. L'auteur y rappelle les luttes menées contre l'État et l'Église pour sauvegarder cette tradition alimentaire, devenue identitaire, pp. 12-17. Nous remercions l'auteur de nous avoir transmis son manuscrit.

${ }^{106}$ Note de Dennis Au du 27 août 2002.

107 «Dance the Hog Trough".

${ }^{108}$ Traduction de la note de Dennis Au du 30 août 2002. 
Bien que ce témoin n'ait pas assisté à une autre cérémonie du genre depuis la noce de son cousin, il affirme qu'elle n'a pas été oubliée et que la population de Newport localité située à environ 16 kilomètres au nord de Monroe et qui compte un grand nombre de descendants des vieilles familles françaises de Détroit - considère qu'il s'agit d'une tradition française. En outre, Dennis Au remarque qu'il y avait à Monroe une salle de danse, disponible pour les réceptions, qui portait le nom de "Hog Trough", c'està-dire "L'Auge à cochon"; il suppose que ce nom aurait pu s'inspirer de la même tradition ${ }^{109}$.

Le maintien de l'expression sans la danse cérémonielle qui lui a donné naissance, par une métaphorisation du rituel, a été signalé en plusieurs endroits de l'Acadie. Nos informatrices de la Nouvelle-Écosse pensent que la plupart des Acadiens de leur génération connaissaient l'expression "danser dans l'auge ${ }^{110}$ ». Il en est de même pour une dame de 86 ans, domiciliée à Rogersville (Northumberland), mais qui a vécu aussi dans le comté de Kent, au NouveauBrunswick: l'expression "danser dans l'auge», qui lui était familière, ne donnait lieu à aucune cérémonie spéciale ${ }^{111}$. Un autre informateur, originaire d'Acadieville (Kent), nous affirma avoir «dansé dans l'auge»; bien que la tradition de danser le jour des noces dans une véritable petite auge existât en parallèle dans son milieu, ce fut pour ce religieux une simple métaphore, car, ce jour-là, il ne put être présent au mariage ${ }^{112}$. Dans l'Île-du-Prince-Édouard aussi, la tradition ne subsisterait plus que dans la métaphore. Selon l'ethnologue Georges Arsenault, cette tradition «n'existe pas, et ne semble pas avoir existé dans la communauté

\footnotetext{
${ }^{109}$ Note de Dennis Au du $1^{\text {er }}$ septembre 2002.

${ }^{110}$ Selon $\mathrm{M}^{\mathrm{mc}}$ Nicole Muise, de l'Université Sainte-Anne, Nouvelle-Écosse, qui nous a communiqué les noms de ces informatrices dans son courriel du 26 mars 2001.

${ }^{111}$ Renseignement communiqué par Lauraine Léger, le 2 novembre 1999.

${ }^{112}$ Témoignage du frère Louis Babineau, eudiste, recueilli à Charlesbourg, le 20 août 1999.
} 
acadienne de l'île-du-Prince-Édouard. Tout au plus, j'ai entendu quelques anciens mentionner l'expression "faire danser une fille dans l'auge à cochons" pour dire qu'une fille se mariait avant sa sœur aînée ${ }^{113}$ ». Cette métaphorisation ne serait pas l'apanage de l'Acadie, puisqu'un octogénaire de l'Ouest canadien la connaissait aussi. Ce citoyen de Gravelbourg, en Saskatchewan, nous confia que, lorsqu'un benjamin se marie avant ses aînés, on dit: "Le jeune a fait danser ses frères dans l'auge.» Cette expression s'applique dans le cas d'une cadette, mais il n'a jamais entendu parler d'une véritable danse dans l'auge ${ }^{144}$.

\section{RÉPARTITION CANADIENNE ET NORD-AMÉRICAINE}

Les enquêtes et consultations diverses que nous menons depuis l'été 1999 composent déjà une image plus cohérente de la diffusion de cette pratique rituelle sur une grande partie du territoire de l'Amérique française et permettent d'apprécier sa vitalité: très présente à l'ouest du Québec, surtout dans le nord de l'Ontario avec des débordements du côté de l'Abitibi-Témiscamingue québécois, dans l'Outaouais ontarien et québécois, ainsi que dans la vallée du Richelieu, toutes régions qui sont en rapport avec la grande banlieue de Montréal, elle se rencontre encore dans l'Acadie du Nouveau-Brunswick et de la Nouvelle-Écosse, dans le nordest des États-Unis et le sud-ouest de l'Ontario; de plus, des expressions reliées à l'auge subsistent ailleurs dans l'Ouest canadien, le Nouveau-Brunswick, le Québec, l'Île-duPrince-Édouard et la Louisiane, sans le rituel cependant. Par contre, cette pratique est totalement inconnue dans plusieurs régions du Québec: la grande région de Québec, le Saguenay-Lac-Saint-Jean, le Bas-du-Fleuve et la Gaspésie, c'est-à-dire l'est du Québec, et les Cantons de l'Est; elle

\footnotetext{
${ }^{113}$ Georges Arsenault, courriel du 26 juillet 1999.

${ }^{114}$ Témoignage de $\mathrm{M}$. Roland Pinsonneault recueilli à Régina le 18 septembre 1999. Né à Saint-Cyprien de Napierville (Québec) en 1914, il est arrivé à Gravelbourg en 1919, à l'âge de 4 ans.
} 
serait en nette régression à Trois-Rivières et à Montréal. Cette facette négative a aussi une grande importance ${ }^{115}$. D'autres témoignages renforcent d'ailleurs ces constatations: un prêtre, originaire de Charlevoix, qui a assisté à de nombreux mariages et en a célébré plusieurs, n'avait jamais entendu parler de cette tradition ${ }^{116}$; une collègue, qui a interrogé pour nous vingt personnes de toutes les paroisses de l'Île d'Orléans «n'a trouvé aucune trace de cette danse», ni à Québec non plus ${ }^{117}$; enfin, un témoin de la région de Montréal avouait à une étudiante que, dans ses vingt ans de prêtrise, il n'avait jamais rencontré ce rituel: «J'ai célébré tant de mariages que je ne peux pas tous les compter. Et je peux dire que j'en ai vu des choses bizarres: des bousculades, des jeux divers et des concours. Mais je n'ai jamais entendu parler de "la danse sur les bas" 118 ."

En somme, ce qui frappe de prime abord, c'est la grande vitalité de ce rituel du mariage dans les régions périphériques du Québec (le Richelieu, l'Abitibi, le Témiscamingue et l'Outaouais), et dans les milieux minoritaires (l'Ontario et le Nouveau-Brunswick), en regard de son absence presque générale au cour des régions du Centre (Québec, TroisRivières et Montréal).

\footnotetext{
$\overline{115}$ Notons qu'il reste encore quelques régions à sonder.

${ }^{116}$ Abbé Noël Simard, le 16 avril 1999.

${ }_{117} \mathrm{M}^{\text {me }}$ Christiane Noël, note du 20 avril 1999.

${ }^{118}$ Annie Gagné, le 5 avril 2000.
} 
TABLEAU 3

Dénombrement et distribution par régions

des témoignages positifs et négatifs sur la danse rituelle de l'aîné célibataire en Amérique française

\begin{tabular}{|c|c|c|c|}
\hline CANADA & Témoignages positifs & négatifs & total \\
\hline Ontario & 180 & 25 & 205 \\
\hline Est & 37 & 5 & \\
\hline Centre & 20 & 9 & \\
\hline Sud-Ouest & 4 & 1 & \\
\hline Nord-Est & 119 & 10 & \\
\hline Acadie & 12 & 7 & 19 \\
\hline Nouveau-Brunswick & 8 & 2 & \\
\hline Nouvelle-Écosse & 3 & 3 & \\
\hline Île-du-Prince-Édouard & 1 & 1 & \\
\hline Terre-Neuve & 0 & 1 & \\
\hline Québec & 42 & 81 & 123 \\
\hline Est & 4 & 35 & \\
\hline Mauricie & 3 & 21 & \\
\hline Centre & 7 & 14 & \\
\hline Montréal & 12 & 11 & \\
\hline Outaouais & 6 & 0 & \\
\hline Témiscamingue & 3 & 0 & \\
\hline Abitibi & 7 & 0 & \\
\hline Ouest & 2 & 4 & 6 \\
\hline Manitoba & (1) & 3 & \\
\hline Saskatchewan & 1 & 1 & \\
\hline Colombie-Britannique & 1 & 0 & \\
\hline États-Unis & 3 & 2 & 5 \\
\hline Maine & 1 & 1 & \\
\hline Michigan & 1 & 1 & \\
\hline Louisiane & 1 & 0 & \\
\hline Haïti & 0 & 1 & 1 \\
\hline Total: & 239 & 120 & 359 \\
\hline
\end{tabular}




\section{Conclusion}

DE LA NÉCESSITÉ D'UN TERRAIN PERMANENT EN ETHNOLOGIE

La danse sur les bas, un rituel du mariage franco-ontarien, n'avait jamais été documentée avant nos recherches ${ }^{119}$. Dans d'autres régions françaises du Canada, où la tradition est connue, des chercheurs sérieux avaient pourtant étudié des sujets voisins, mais, ignorant eux-mêmes cette tradition, les missions qu'ils y menèrent ne purent en attester ni la présence ni l'absence. Lauraine Léger, qui a innové par ses enquêtes sur le folklore juridique en Acadie, aurait normalement dû en traiter dans le chapitre qu'elle consacre à la "sanction satirique ${ }^{120}$ ». Mais, inconnue d'elle, de sa famille et de son village, cette tradition n'apparut ni dans son questionnaire, modelé d'après les travaux du Français René Maunier, ni, conséquence logique, dans les données recueillies. Néanmoins, cette tradition est toujours vivante dans le comté de Kent, comme elle a bien voulu le vérifier pour nous par la suite ${ }^{121}$. De même, Simonne Voyer, de Montréal, qui s'est spécialisée dans l'étude des danses populaires et qui a parcouru pour ses grands travaux tout l'est du Canada, n'a jamais entendu parler de cette danse rituelle, alors que, dans la banlieue de la région qu'elle habitait, elle se pratique toujours ${ }^{122}$. Il en va de même pour l'enquête sur la danse que mena Barbara Le

\footnotetext{
${ }^{119}$ Les Archives de folklore de l'université Laval (AFUL) ne contenaient rien à ce sujet selon la note de l'archiviste Jean Coulombe, en date du 5 août 1999. Vers la même époque, notre collègue Ronald Labelle, du Centre d'études acadiennes (CÉA), fit la même constatation pour l'Acadie; à Sudbury, le Centre franco-ontarien de folklore (CFOF) ne possédait aucun renseignement non plus.

${ }^{120}$ Lauraine Léger, Les Sanctions populaires en Acadie. Région du comté de Kent, [Montréal], Leméac, "Connaissance», [1978], 186 pages. Elle a mené ses enquêtes entre 1968 et 1971.

${ }^{121}$ C'est ce qu'elle nous affirma dans une conversation téléphonique, le 2 novembre 1999.

${ }^{122}$ Simonne Voyer, La Danse traditionnelle dans l'est du Canada. Quadrilles et cotillons, Québec, PUL, «Ethnologie de l'Amérique française», 1986, [9]-509 pages. On n'en trouve pas mention à la section «danse et vie sociale» (pp. 2639) du chapitre "La danse au Canada du XVIII" au XX" siècle".
} 
Blanc à Chéticamp, dans l'île-du-Cap-Breton ${ }^{123}$, et pour l'étude de Robert-Lionel Séguin ${ }^{124}$. Enfin, l'équipe de Gérard Bouchard, qui ouvrait en 1986 un chantier tout spécialement dévolu aux rituels du mariage, n'a inclus une question sur ce rite de passage que dans la dernière version de son questionnaire en $1990^{125}$; cet ajout tardif a quand même permis de noter l'état de ce rituel dans certains terroirs québécois ${ }^{126}$. À la prudence, s'ajoute donc l'humilité du chercheur devant son ignorance des questions qu'il n'a pas spécialement étudiées. Dans notre cas, l'humilité doit être d'autant plus grande que notre ignorance était en outre entachée de préjugés.

Se limiter aux seules données disponibles aurait donc été

\footnotetext{
${ }^{123}$ Barbara Le Blanc, op. cit.; voir son questionnaire, pp. 230-236.

${ }^{124}$ Robert-Lionel Séguin, La Danse traditionnelle au Québec, Sillery, Presses de l'Université du Québec, 1986, 176 pages. La section «À la veillée et à la noce»" du chapitre "Quand danse-t-on?» n'en porte pas trace (pp. [99]-107).

${ }^{125}$ La première version de la grille d'analyse ne porte aucune mention de cette pratique: "Les Rituels du mariage au Saguenay et dans Charlevoix: grille d'analyse», par Anne-Marie Desdouits, Gérard Bouchard, Marie-Josée Huot et Jean-Claude Dupont, document II-C-119 du Programme de recherches sur les sociétés régionales (SOREP), juillet 1986, p. 47: XII-La noce: E-Divertissements: 6 . Danses [rien]; 8 . Autres rituels: c) autres activités [rien]. S'inspirant des données acadiennes, la version révisée contient, sous XIII-E-8f, 1. "faire manger des parents, des amis dans l'auge (en signe de dérision)», p. 62: «Les Rituels du mariage dans les régions du Québec: grille d'analyse (deuxième version)", par Anne-Marie Desdouits, Gérard Bouchard, Josée Gauthier, Marie-Josée Huot et Jean-Claude Dupont, document II-C-172 (SOREP), octobre 1990. Dans le document II-C-184, de septembre 1991, cette entrée sera modifiée en "III.4. Faire danser des parents, des amis dans l'auge: IV.1. Intiative de qui?; IV.2. Moment», pp. 44-45: «[Mariages] Grille de repérage», par Gérard Bouchard, Anne-Marie Desdouits, René Hardy et Josée Gauthier.

${ }^{126}$ Dans son envoi du 23 août 2000 , en nous communiquant les réponses alors disponibles, Josée Gauthier notait: "Vous remarquerez tout de suite que les résultats ne sont pas nombreux et il est malheureux que la banque ne soit pas tout à fait complétée, car je suis certaine qu'il y aurait eu attestation de ce rite du côté ouest de la province. Pour ce qui concerne l'est du Québec, je me permets de vous rappeler que ce thème du rituel du mariage n'a été introduit dans l'enquête qu'en 1990, soit après que nous ayons pratiquement complété le terrain dans cette partie du Québec. Ceci explique d'ailleurs l'absence (ou presque) de réponses à cette pratique coutumière du côté de Charlevoix et du Saguenay.»
} 
une option carrément désastreuse qui, en plus de dénoter une imprévoyance stupéfiante et une impuissance à imaginer des projets de recherche, se serait avérée une politique à courte vue conduisant fatalement à l'asphyxie de la discipline. Puisque la spécificité du travail de l'ethnologue repose justement sur la qualité et la pertinence de sa documentation - obtenue par l'enquête directe, sur le terrain, auprès des dépositaires, et donc des premiers témoins, de la tradition - l'abandon de l'enquête orale comme voie privilégiée de sa documentation scientifique le cantonnerait dans l'utilisation des sources secondaires et tertiaires manuscrites ou imprimées -, incomplètes ou inappropriées, ce que le plus ordinaire des historiens fait déjà.

Quant à «l'impatience de la synthèse», Pierre Saintyves redoutait qu'on ne "transform[â]t en vérités, sinon en dogmes, les hypothèses et les théories toutes provisoires que l'on pourrait être tenté d'édifier sur des fondations ruineuses où les masses de faits incertains qu'on y aurait maçonnés s'effondreraient rapidement». Il en notait surtout le caractère pernicieux: «Un excessif appétit de synthèse, non seulement implique un certain manque de philosophie et de patience scientifiques, mais conduit facilement à tenir en un relatif dédain l'observation et la récolte des faits, à les considérer comme de basses œuvres scientifiques ${ }^{127}$." Ce à quoi il opposait:

Aucun de ceux qui ont lu les travaux de Durkheim [. .] ou quelques-uns des manuels rédigés par des maîtres français [. .] ne se permettra de croire que l'observation des faits et leur description ne font point partie du travail scientifique, et que, seule, l'explication des faits relève de la sociologie. Tous nous dirons, avec Tarde aussi bien qu'avec Durkheim: il faut aller des choses aux idées ou des faits aux lois et tout d'abord observer, recueillir, analyser les faits sociaux, avec le même soin que le chimiste et le naturaliste apportent à la récolte et à l'analyse des faits qui les intéressent ${ }^{128}$.

$\overline{{ }_{127}}$ Pierre Saintyves, Manuel de folklore, Paris, Émile Nourry, 1936, p. 46. ${ }^{128}$ Ibid., p. 47. 
Telle est la démarche courante de l'ethnologue, comme c'est aussi la pratique prudente de nombreux scientifiques. Le retour à l'observation rigoureuse des faits - par le terrain en ethnologie - favorise l'intelligence et l'interprétation correcte de problèmes qui resteraient autrement insolubles ou qu'on alignerait de force sur des théories éphémères. N'eût été de cette méthode, notre étude sur la transmission d'un conte animalier fût demeurée incomplète et nos conclusions conjecturales ${ }^{129}$. De même, les recherches que nous avons entamées sur la danse rituelle de l'aîné célibataire, exécutée le jour du mariage de son cadet, durent d'autant plus obligatoirement emprunter ce parcours qu'il n'y avait encore rien d'écrit sur cette tradition franco-ontarienne des plus vivantes. C'est pourquoi notre dette est grande envers ce pays français qui a assuré sa large part dans la production de l'image rémanente de cette sanction populaire.

\section{REMERCIEMENTS}

Nous tenons à remercier toutes les personnes et les institutions qui ont encouragé cette étude: nos étudiants d'abord, qui nous ont éveillé à cette tradition et ont appuyé concrètement nos efforts, et notamment, parmi ceux-ci, Lucie Beaupré, auteur de la première description franco-ontarienne et fidèle collaboratrice de notre département; les centres et toutes les personnes qui nous ont généreusement offert leurs témoignages et dont on trouvera les noms en note sous leur contribution; l'Université de Sudbury qui nous a permis de présenter un premier exposé de cette recherche à Poitiers, en mai 2000; enfin, nos collègues de la Société Charlevoix, particulièrement Gaétan Gervais et Fernand Ouellet, qui ont amicalement proposé leurs commentaires pertinents dans un délai restreint.

${ }^{129}$ J.-P. Pichette, "Le Lynx et le renard". Un relais déroutant dans la transmission du conte populaire français en Ontario», dans les Cahiers Charlevoix, Sudbury, Prise de parole et Société Charlevoix, vol. I, 1995, pp. 169-240. 


\section{ANNEXE: «MANGER DE L'AVOINE» ET «DONNER LA PELLE»}

«MANGER DE L'AVOINE»

Au Canada, c'est à Jacques Viger (1787-1858) que revient la première mention de l'expression "manger de l'avoine»; dans les listes de mots et d'expressions qu'il a compilées pour sa Néologie canadienne, elle figure trois fois à peu près sans explication: "manger de l'avoine couper l'herbe sous le pied», "manger de l'avoine» et "faire manger de l'avoine [à] quelqu'un ${ }^{130}$ ". Elle apparaît ensuite dans le roman de Philippe Aubert de Gaspé fils, Le Chercheur de trésors, dont la première édition date de 1837. Bien que son auteur n'ait pas cru nécessaire d'en fournir l'explication, elle s'éclaire par le contexte de la nouvelle "L'Etranger». Le soir du mardi gras, Rose Latulipe délaisse son fiancé, Gabriel Lepard, à qui elle "en faisait passer» à l'occasion, pour accepter l'invitation de danser toute la soirée avec le bel étranger qui vient de survenir; on trouve alors ce passage: "L'inconnu n'abandonna pas Rose du reste de la soirée, en sorte que le pauvre Gabriel, renfrogné dans un coin, ne paraissait pas manger son avoine de trop bon appétit ${ }^{131}$.»

${ }^{130}$ Néologie canadienne de Jacques Viger (Manuscrits de 1810), édition avec étude linguistique par Suzelle Blais, Préface d'André Lapierre, Ottawa, PUO, "Amérique française" 5, [1998], pp. 245, 259 et 263.

${ }^{131}$ Philippe Aubert de Gaspé fils, Le Chercheur de trésors ou l'Influence d'un 
Par la suite, les lexicographes attesteront régulièrement l'expression "manger de l'avoine» et son contraire «faire manger de l'avoine». Oscar Dunn note, dans son Glossaire franco-canadien, en 1880: «Avoine. "Faire manger de l'avoine à quelqu'un." Pop. Courtiser sa blonde, lui présent, et paraître avoir l'avantage sur lui ${ }^{132}$.» Sylva Clapin consigne dans son Dictionnaire canadien-français en 1894: «Avoine (manger de l'), loc., [Ê]tre supplanté par un rival dans l'affection de celle qu'on aime./On dit aussi: - Recevoir son avoine, c.-à-d. recevoir congé de sa belle./v. le mot PeLLE ${ }^{133}$.» En 1909, Narcisse-Eutrope Dionne reprend cette entrée avec une définition qui ne gagne rien en clarté: «Avoine, n. f. Faire manger de l'avoine à quelqu'un, le fait d'un jeune homme qui courtise une jeune fille avec plus d'avantage que tout autre ${ }^{134}$.» Albert Laberge présente dans son roman La Scouine, publié en 1918, une intéressante anecdote qui en éclaire mieux le sens. Alors que le timide Charlot se prépare à se déclarer à Célina, le valet de ferme Guilbault "se mit en tête de le supplanter»; charmée par le nouveau venu, Célina n'adressa pas deux mots à son prétendant: "Découragé par cet échec, Charlot résolut de ne plus s'exposer à manger d'avoine ${ }^{135}$." Louis-Philippe Geoffrion donnera l'explication la plus complète de cette locution dans le premier tome de ses Zigzags autour de nos parlers en 1924:

Manger de l'avoine, faire manger de l'avoine. Il s'agit ici, non pas de picotin, mais de procédés dans les relations de société./ Quand plusieurs garçons se rencontrent dans une famille où ils

livre, chapitre cinquième "L'Étranger» [légende de Rose Latulipe], Québec, Imprimerie de Léger Brousseau, 1878 [1837 pour l'édition originale], p. 58.

${ }_{132}$ Oscar Dunn, Glossaire franco-canadien, reproduction de l'édition originale de 1880, Québec, PUL, "Langue française au Québec», 1976, p. 14.

${ }^{133}$ Sylva Clapin, Dictionnaire canadien-français, reproduction de l'édition originale de 1894, Québec, PUL, «Langue française au Québec», 1974, p. 31.

${ }^{134}$ Narcisse-Eutrope Dionne, Le Parler populaire des Canadiens français, reproduction de l'édition originale de 1909, Québec, PUL, «Langue française au Québec», 1974, p. 47.

${ }^{135}$ Albert Laberge, La Scouine, Montréal, L'Actuelle, 1972 [1918], p. 59. 
se sont rendus avec l'intention de courtiser la jeune fille de la maison, celui que cette jeune fille honore de ses attentions, celui à qui elle permet, par exemple, de s'approcher et de lui conter fleurettes à l'écart durant toute la soirée, fait manger de l'avoine à ses rivaux, et ceux-ci. . mangent de l'avoine./En termes d'amoureux, manger de l'avoine, c'est donc être supplanté par ses rivaux, et faire manger de l'avoine, c'est supplanter ses rivaux./Ces deux locutions sont presque françaises. En effet, au témoignage de Bescherelle, on dit fort bien en France: "Cet homme a reçu de l'avoine», pour: Cet homme a été rebuté par celle qu'il aime./Il va sans dire que, dans ces locutions comme dans toutes autres, avoine se prononce aussi avouène, awène, et même aveine comme dans l'ancien français ${ }^{136}$.

C'est cette définition qui sera reprise et abrégée dans le Glossaire du parler français au Canada en $1930^{137}$; on lui ajoutera l'entrée "Manger de l'avoine = être supplanté comme amoureux ${ }^{138}$ ".

Entre-temps, en 1927, Pascal Poirier aura relevé cette expression en Acadie, mais il lui accolera un autre équivalent acadien: "Avoine. Manger de l'avoine, c'est, pour un prétendant, recevoir la pelle, être éconduit par sa belle $^{139}$." À son tour, Geneviève Massignon la trouvera en 1946 dans neuf de ses 18 lieux d'enquête sur les parlers d'Acadie - au Nouveau-Brunswick, en Nouvelle-Ecosse, à l'Île-du-Prince-Édouard et au Québec - , et en rendra

${ }^{136}$ Louis-Philippe Geoffrion, Zigzags autour de nos parlers. Simples notes, Préface par M. le juge Adjutor Rivard, Première série, Québec, Chez l'auteur, [1924; deuxième édition en 1925], pp. 91-92.

${ }_{137}$ Société du parler français au Canada, Glossaire du parler français au Canada [Réimpression de l'édition publiée en 1930], Québec, PUL, 1968, p. 81: «Avoine». Léandre Bergeron, qui s'est fort inspiré de cet ouvrage pour composer son Dictionnaire de la langue québécoise ([Montréal], VLB éditeur, [1980]), lui accorde aussi deux entrées: «Avoine n.f. Faire manger de l'avoine à quelqu'un - Provoquer la jalousie d'un amoureux. Manger de l'avoine Souffrir de la jalousie provoquée par un rival dans les relations amoureuses" (Ibid., p. 57) et «Manger v. tr. [. .] Manger d'l'avoine - Être supplanté comme amoureux.» (Ibid., p. 307).

${ }^{138}$ Ibid., p. 437: sous l'entrée "Manger», c'est le neuvième sens.

139 Pascal Poirier, Le Glossaire acadien, édition critique établie par Pierre M. Gérin, [Moncton], Éditions d'Acadie et Centre d'études acadiennes, [1993; le manuscrit est de 1927I, p. 42. 
compte en 1962 à la question 1724 «Supplanter un rival: couper l'herbe sous le pied; faire manger de l'avoine ${ }^{140}$ ".

Toutefois, la description qu'en donne Maurice Lorent, qui la signale également dans la Beauce québécoise en 1977, va au delà des versions antérieures qui la limitent à une expression verbale, sans geste; c'est un véritable rite de congédiement qu'il présente:

Manger [mâjé] v. tr. 1. Manger de l'avoine. Di[onne]. Gl[ossaire]. Être congédié comme amoureux. "Quand une fille recevait pour la dernière fois son amoureux avec qui elle ne désirait plus sortir, elle faisait mettre discrètement une poignée d'avoine dans une poche de son veston: ça s'appelait faire manger de l'avoine; quant au garçon, il avait mangé de l'avoine." (Beauce)./Syn.: recevoir la *pelle avec le manche ${ }^{141}$.

L'Atlas linguistique de l'Est du Canada (ALEC), dont les enquêtes ont été menées de 1969 à 1973 et les résultats publiés en 1980 par Gaston Dulong et Gaston Bergeron, énumère, dans les réponses à la question 1881 , toute une série d'expressions, dont celle qui nous intéresse ici:

Q. 1881 Éconduire son amoureux: casser [. .], casser avec quelqu'un [. .], casser ses amours [. .], casser sa pelle [. .], donner sa pelle ou donner la pelle à quelqu'un [. .], envoyer la pelle [. .], une pelle [. . ] ou sa pelle à quelqu'un [. . ], donner son biscuit [ . .], donner (son) congé [. .], son chapeau [. .], mettre à l'herbe [. . ], faire manger de l'avoine [. .], avoir la pelle puis le manche $[. .]^{142}$.

Et les auteurs commentent: " "Donner, envoyer la pelle", c'est éconduire un amoureux par écrit [. .] et c'est refuser un prétendant qui fait la "grande demande" en mariage [ . . ./."Faire manger de l'avoine", c'est éconduire un amou-

${ }^{140}$ Geneviève Massignon, Les Parlers français d'Acadie. Enquête linguistique, Paris, Librairie G. Klincksieck, [1962], tome II, p. 654.

${ }^{141}$ Maurice Lorent, Le Parler populaire de la Beauce, [Montréal], Leméac, 1977, p. 104. L'auteur ajoute aussi une autre expression ayant le même sens, mais qui s'emploie dans un contexte différent: « 2 . Manger son fromage: digérer sa défaite (ou celle de son candidat) à une élection. "À ceux qui perdent leurs élections on demande s'ils ont mangé leur fromage" (Beauce).» ${ }^{142}$ Dulong et Bergeron, ALEC, op. cit., pp. 2859-2861. 
reux en présence de son rival $[. .]^{143}$.» Par contre, à la question 1882, "manger de l'avoine " devient incontournable: «Q. 1882 Être supplanté par un rival : manger de l'avoine [. .], manger sa portion [. .], manger sa portion d'avoine [. .], manger de l'avoine à grosse portion [. .], avoir sa portion [. .], donner de l'avoine [. .] ${ }^{144}$.» Le commentaire précise: "Manger de l'avoine" signifie être supplanté, le plus souvent d'une façon temporaire, le temps d'une danse ou d'une soirée par exemple./C'est la jeune fille qui semble avoir l'avantage et c'est elle qui "fait manger de l'avoine" à un de ses prétendants.» Plus loin, les auteurs poursuivent: "[. .] Une jeune fille qui aurait été temporairement délaissée par son ami lui dira:"Tu m'as fait manger de l'avoine, je vais garder le foin pour la vache" [. . $]^{145}$.» Le dépouillement des données fournies par les auteurs de l'ALEC montre que la locution «manger de l'avoine" est répandue partout au Québec, en Ontario, au Nouveau-Brunswick; elle est aussi connue à l'Île-du-PrinceÉdouard et en Nouvelle-Écosse. On pourrait la qualifier de générale étant donné que 159 des 168 témoins interrogés la connaissaient.

Pour leur part, Thomas Lavoie, Gaston Bergeron et Michelle Côté en feront aussi état dans Les Parlers français de Charlevoix, du Saguenay, du Lac-Saint-Jean et de la Côte-Nord, publié en 1985, à partir des enquêtes effectuées entre 1972 et 1976; cette locution figure dans les réponses aux questions 2782 et 2783 de leur ouvrage: «Q. 2782 Éconduire son amoureux, être éconduit: avoir son biscuit [. .], donner son biscuit [. . ], casser [. .], casser les amours [. .], mettre à l'herbe [. .], envoyer à l'herbe [. .], envoyer en pacage [. .]»; et «Q. 2783 Supplanter un rival en amour: (faire) manger de l'avoine [. . ], manger sa

\footnotetext{
${ }^{143}$ Ibid., p. 2862.

144 Ibid., pp. 2862-2863.

${ }^{145}$ Ibid., p. 2864.
} 
portion [. . $]^{146}$ ». Il appert qu'éconduire son amoureux se dit "casser (les amours)" dans 30 des 32 points informatisés de cette enquête ou "mettre (ou envoyer) à l'herbe" dans 25 des cas; mais tous les points d'enquête connaissent l'expression «(faire) manger de l'avoine» pour supplanter son amoureux.

Ainsi, cette expression populaire, dans sa forme active ou dans sa forme passive, est dûment attestée partout dans la francophonie canadienne et de façon ininterrompue depuis bientôt deux siècles ${ }^{147}$. Peut-être même survit-elle à une tradition évanouie où, le geste accompagnant la parole, la jeune fille, pour prendre congé d'un amoureux qui ne l'intéressait pas, faisait déposer un peu d'avoine dans le vêtement de ce dernier, de la manière dont Maurice Lorent l'a décrite et qui s'avère une attestation isolée. Pourtant la présence de foin et de grain, dans certaines mises en scène du rituel, particulièrement en Ontario et en Acadie, appuie cette hypothèse comme encore la mystification suivante qu'on destinait à l'aîné non marié: à Sainte-Rose-du-Lac, au Manitoba, il n'y avait pas de danse pour le sanctionner, mais on attachait un petit sac de blé à la ceinture du célibataire le soir des noces de son cadet; le tour était réussi si l'opération était exécutée sans qu'il s'en aperçoive ${ }^{148}$. Cette plaisanterie est à rapprocher d'une autre blague destinée à surprendre l'aîné célibataire: le jour des noces, durant la soirée, on attache un chat par la queue à la jambe du vieux garçon ou de la vieille fille; cette

${ }^{146}$ Thomas Lavoie, Gaston Bergeron et Michelle Côté, Les Parlers français de Charlevoix, du Saguenay, du Lac-Saint-Jean et de la Côte-Nord, [Québec], Publications du Québec, [Office de la langue française], [1985], v. 4, pp. 1194 1195.

${ }^{147}$ Pour d'autres références, on consultera l' «Index lexicologique québécois (ILQ)" préparé par le Trésor de la langue française au Québec (TLFQ), une section du Centre international de recherche en aménagement linguistique (CIRAL) de l'université Laval.

${ }^{148}$ Renseignement communiqué par M. Kenneth-Roy Bonin, le 15 juin 2001, dont la mère, d'origine flamande, avait eu connaissance de cette pratique au Canada. 
tradition se pratique à Saint-Côme (Joliette) et elle illustrerait l'expression «lâcher la queue de la chatte», qui signifie, selon le témoin, se marier: l'aîné non marié n'ayant pas encore lâché la queue de la chatte, on la lui attache par surprise à la jambe pour se moquer de lui ${ }^{149}$.

\section{" DONNER LA PELLE "}

Dans les citations précédentes, nous avons rencontré une autre expression, équivalente au point de vue sémantique, connue tant au Québec qu'en Acadie: «donner la pelle» ou "attraper la pelle». Clapin relève ces deux formes en 1894: "Pelle (avoir, recevoir la), loc., Manger de l'avoine (v. ce mot), c.-à-d. être supplanté auprès de sa belle par un rival. Allusion au coup de pelle dont on gratifie un fâcheux, un importun ${ }^{150}$." Dionne fait de même pour le Québec, sans localisation, en 1909: «Pelle, n. f. - Donner la pelle, vouer un amoureux à un échec. - Recevoir la pelle, amoureux éconduit par sa blonde ${ }^{151}$." Puis Pascal Poirier les consigne à son tour; d'abord, en 1927, dans le manuscrit de son Glossaire acadien: "Une jeune fille donne la pelle à un garçon lorsqu'elle refuse de l'épouser. Le prétendant qui fait la grand-demande, et qui est éconduit, attrape la pelle ${ }^{152}$ "; et en 1928: "Quand, à la grand demande [en note: la demande en mariage], un prétendant est refusé par la jeune fille, il attrappe [sic] la pelle, et ne s'en vante pas $^{153}$." Le Glossaire du parler français au Canada les inscrira à son tour, pour le Québec, mais toujours sans localisation:

\footnotetext{
${ }^{149}$ Renseignement communiqué par M. Lucien Ouellet, le $\mathrm{l}^{\text {er }}$ novembre 1999. Dans le Glossaire du parler français au Canada, op. cit., l'expression «lâcher la queue du chat" signifie plutôt: "être parrain ou marraine pour la première fois. Ex.: Il n'a jamais encore lâché la queue du chat = il n'a jamais été parrain " (p. 192).

${ }^{150}$ Clapin, op. cit., p. 242.

${ }^{151}$ Dionne, op. cit., p. 492.

${ }^{152}$ Poirier, op. cit., p. 304.

${ }^{153}$ Pascal Poirier, Le Parler franco-acadien et ses origines, Québec, Imprimerie franciscaine missionnaire, 1928, p. 245.
} 
Pelle (pèl) s. f. $1^{\circ}$ Donner la pelle = éconduire (un prétendant, en parlant d'une jeune fille qui refuse sa main à un jeune homme ou qui lui fait comprendre qu'il est inutile pour lui de la courtiser). - Avoir la pelle, recevoir la pelle = être éconduit (en parlant du jeune homme refusé)./Dial.V. Rev. du Traditionnisme, mars 1906, pp. $74-75^{154}$.

Geneviève Massignon ne manquera pas de les rencontrer en Acadie en cinq points d'enquête - au Nouveau-Brunswick et en Nouvelle-Écosse - et elle inscrira comme réponses à la question 1723 "Elle l'a éconduit»: "elle lui a donné la pelle», "il a attrapé la pelle» avec d'autres expressions ${ }^{155}$.

Hors de l'Acadie, Maurice Lorent sera le premier à localiser ces expressions en Beauce:

Pelle [pèl] s. f. Donner la... avec le manche, loc. verb. Éconduire son prétendant, interrompre les rencontres avec son amoureux; de ce dernier on dit qu' «il a reçu la pelle avec le manche». Di[onne]. Gl[ossaire]. Mass[ignon]. «Sam'di soir ma sœur a donné la pelle avec le manche à son ami de garçon.» (Beauce)./ Syn.: faire *manger de l'avoine ${ }^{156}$.

Enfin, l'Atlas linguistique de l'Est du Canada fournira ces expressions, avec plusieurs autres, comme réponses aux questions 1881 et 1882 déjà citées. Étonnamment, l'expression «donner la pelle» ou "attraper la pelle», que les glossaires acadiens consignent régulièrement, n'est attestée que par deux témoins, du Nouveau-Brunswick et de la Nouvelle-Écosse, sur les neuf informateurs acadiens interrogés par l'ALEC. Par contre, 63 des 151 témoins de la plupart des régions du Québec la connaissaient aussi; les habitants de la région de Québec, de Charlevoix et du Saguenay-Lac-Saint-Jean, de l'Outaouais québécois et de l'Ontario l'ignoraient cependant. Les auteurs des Parlers populaires de Charlevoix et de ses régions voisines n'ont pas non plus relevé cette expression ${ }^{157}$.

${ }^{154}$ Société du parler français au Canada, op. cit., p. 504.

${ }^{155}$ Massignon, op. cit., p. 654.

${ }^{156}$ Lorent, op. cit., p. 119.

${ }^{157}$ D'autres expressions ont le même sens: en 1946, Geneviève Massignon a 
Ici encore, les lexicographes, qui se sont intéressés aux mots, auraient omis de noter que l'expression était porteuse d'un rituel. Voici ce qu'a recueilli l'ethnologue JeanClaude Dupont:

Il existe différentes façons de signifier à un amoureux qu'il n'est pas le bienvenu [:] [selon une informatrice de Petit-Rocher (Gloucester),] «La fille se faisait fabriquer une petite pelle en bois et l'envoyait porter au garçon». De là l'expression encore très populaire: Donner sa pelle à quelqu'un, ou recevoir sa pelle. À Saint-Anselme, [selon trois autres informatrices de Westmoreland,] on invitait le garçon à manger de la poutine râpée et on avait mis une petite pelle en bois dans la pâte ${ }^{158}$.

De même, nous l'avons vu, l'expression «danser dans l'auge" dure, et garde le sens approprié, en l'absence de tout rituel.

aussi recueilli l'expression "elle lui a donné son chapeau", toujours dans le sens d'éconduire son amoureux, à Sainte-Anne, Madawaska, au NouveauBrunswick (op. cit., p. 654: réponse à la question 1723). Récemment, Yves Cormier, dans son Dictionnaire du français acadien ([Montréal], Fides, [1999], p. 132), reprenait cette attestation: "On dit aussi donner son chapeau au sens d'"éconduire son amoureux" (en Acadie et au Québec)".

${ }^{158}$ Jean-Claude Dupont, op. cit., p. 221. 